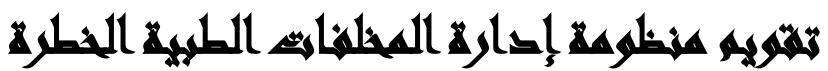

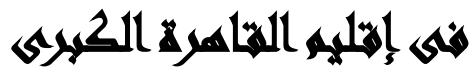

$[1 \mathrm{~T}]$

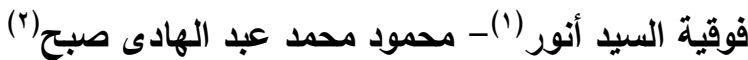

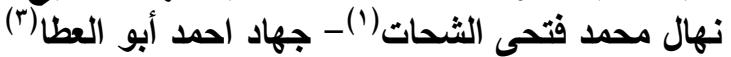

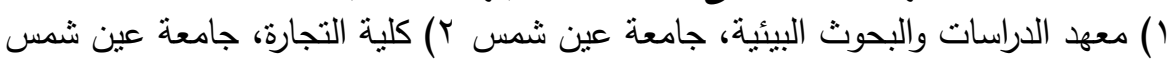
r) كلية الطب القصر العيني، جامعة القاهرة

\section{المستخلي}

تهدف الدراسة إلى تقويم منظومة إدارة المخلفات الطبية الخطرة في محافظات القاهرة

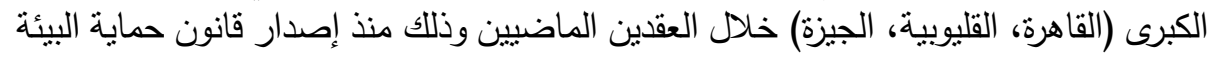

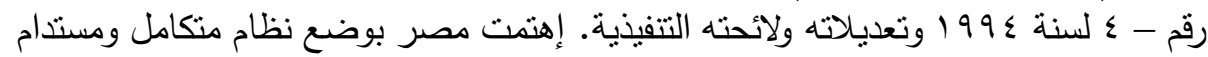

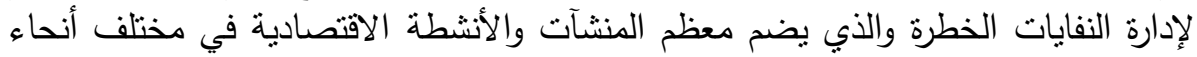

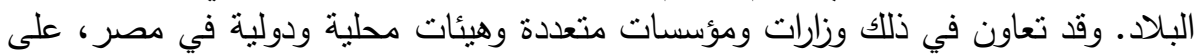

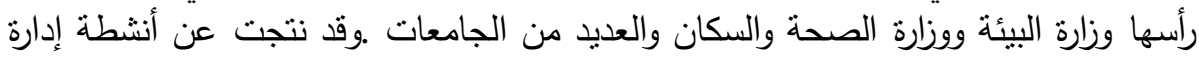

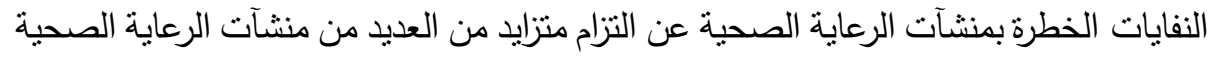

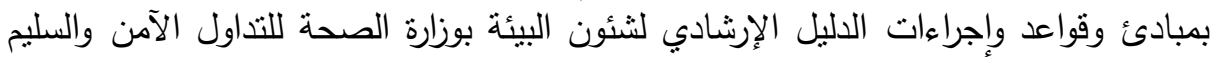

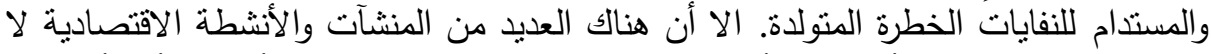

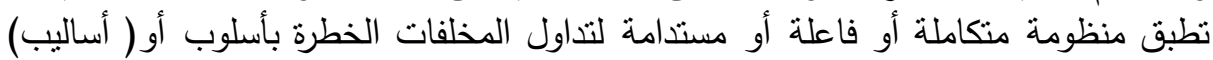

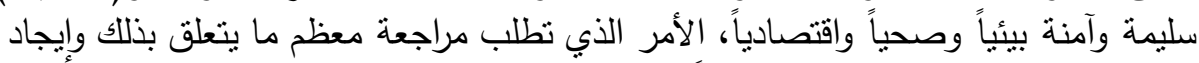
الحلول المناسبة البديلة التي تحقق توافقاً مع القانون واشتراطاتها

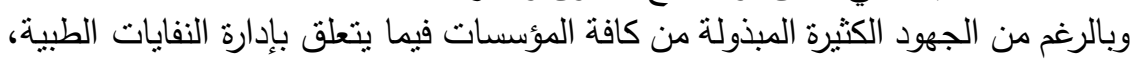

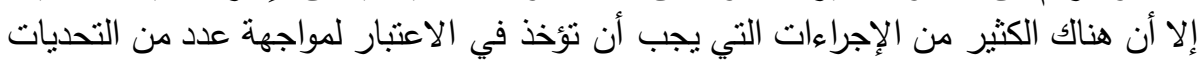

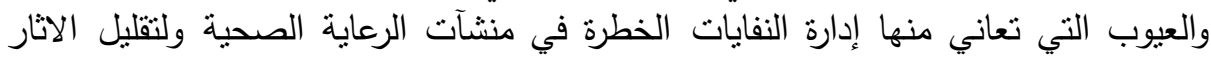

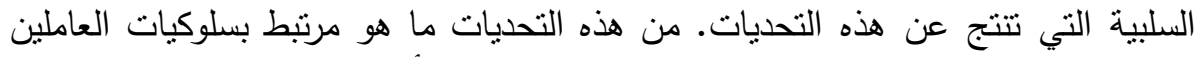

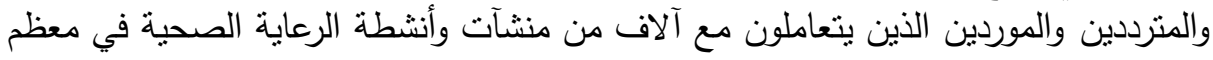

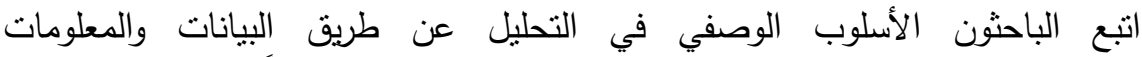
والإحصائيات المتعلقة بموضوع الدراسة ولقد تم توزيع مفردات العينة طبقاً للنوع (ذكور ، إناث)

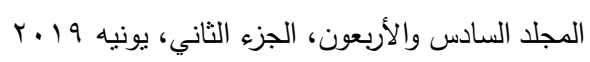


والمستوى التعليمي (مؤهل جامعي فيما فوق، مؤهل متوسط، مؤهل متوسط فأقل) والفئة

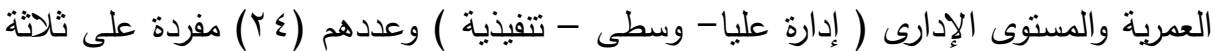

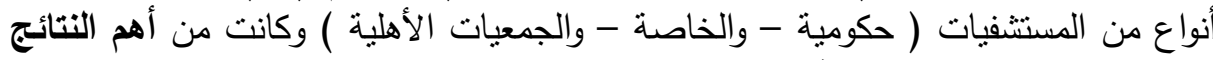
التي توصلت إليها هذه الاراسة:

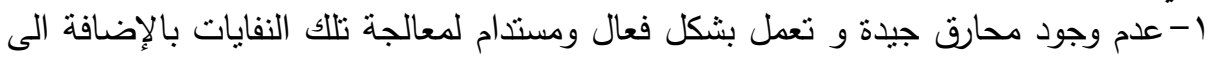

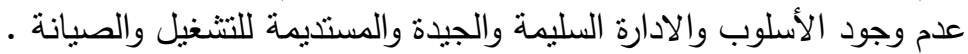
r-المستشفيات في محافظات القاهرة الكبرى تفتقر الى نظام الألى الادارة الجيدة لنفاياتها من حيث الاسلوب المنبع في التعامل مع عمليات جمع ونقل وخزن النفات النفايات. أهم توصيات الاراسة:

1-البدء فى إيجاد حل شامل ومتكامل ومستدام ويكون الانسب صحياً وبيئياً واقتصادياً لإدارة

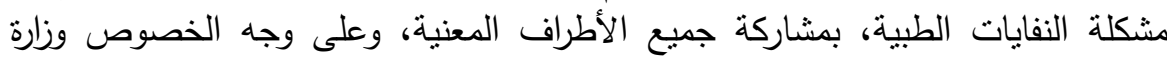

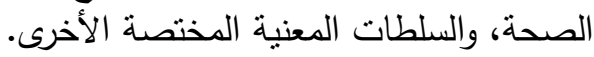

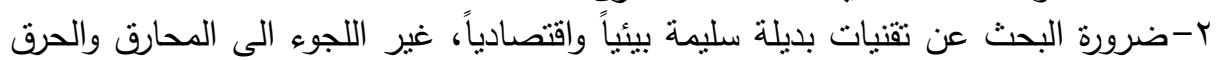

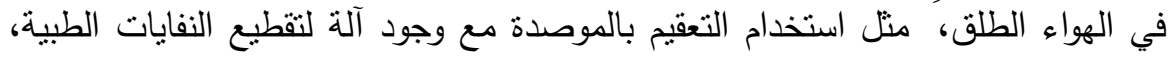

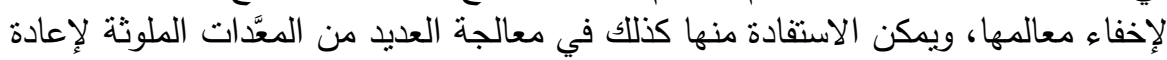

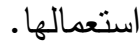

\section{ranadl}

في كثثر من الأحوال نم الحديث عن مخلفات أنشطة ومنشأت الرعاية الصحية أو النفايات الطبية ومدى خطورتها وكيفية التخلص منها وخاصة أن جزء منها يعتبر ضمن التهن

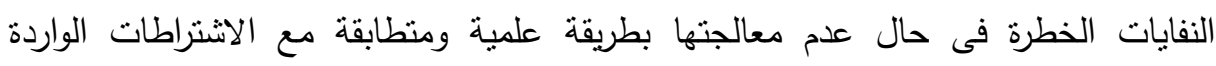

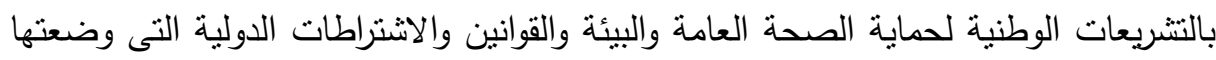
منظمة الصحة العالمية وسواها من المنظمات العالمية منل برنامج الأمم المتحدة للبيئة. ان هذه النفايات الناتجة عن منشأت الرعاية الصحية هى إحدى أخطر المشكلات البيئية لاى

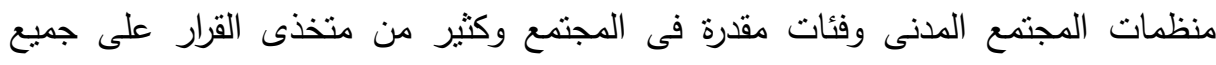
المستويات لها لهذه المخلفات من أضرار صحية وبيئية، ومن المعوقات التى نواجه أنظمة فئي إدارة نفايات منشأت الرعاية الصحية مايلى: 
1-عدم الألنزام بنظام تصنيف وفرز لمخلفات أنشطة ومنشات الرعاية الصحية مما ساهم فى الصى اختلاط المخلفات الخطرة فى تلك المنشات بغيرها من المخلفات غير الخطرة التى يمكن

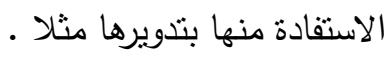

r-نقل مخلفات أنشطة ومنشات الرعاية الصحية إلى أماكن التخلص النهائى بواسطة مركبات

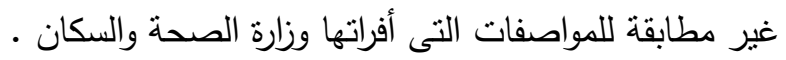

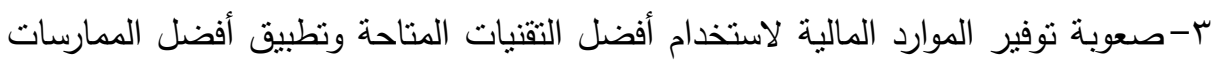

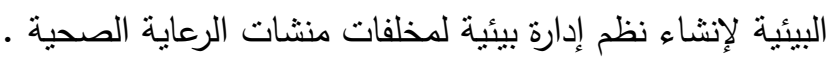

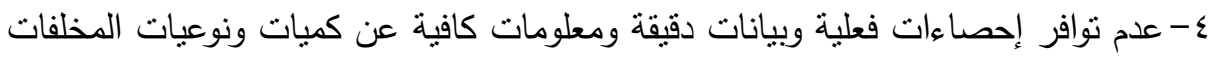

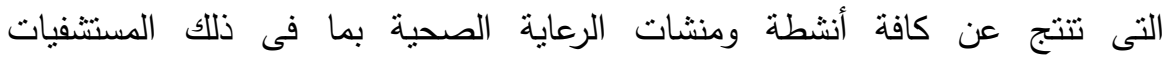
والمستوصفيات والمراكز الطبية المتخصصة والعيادات الخاصة ومعامل (مختبرات) الفحوص الطبية ومراكز الأبحاث والصيدليات . ه- عدم كفاية أجزة وتقنيات معالجة النفايات الطبية الخطرة مثل ألات الترميد (الحرق

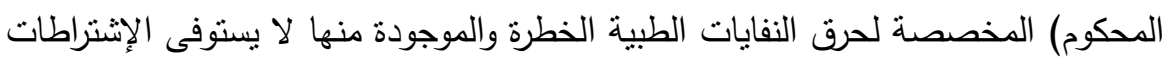

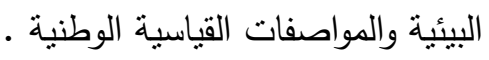
يعود كل ما سبق إلى عدم تطبيق الاستراتيجيات والخطط والسياسات والإجراءات

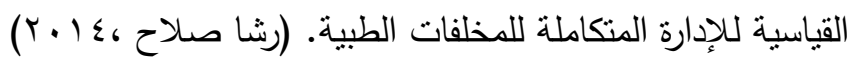
على المستوى الوطنى أصدرت وزارة الصحة والسكان قائمة بكافة أنواع النفايات الطبية الخطرة بقرار وزير الصحة والسكان رقم

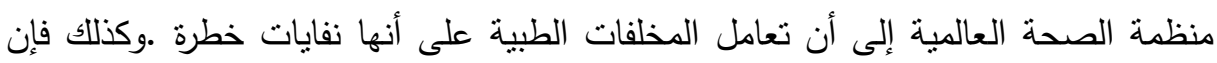
وكالة حماية البيئة (EPA ) بالولايات المتحدة الأمريكية حددت هذه المخلفات على أنها

ومن المسلم به الإن أن جزءاً هاماً من المخلفات الطبية هى من بين أكثر المخلفات

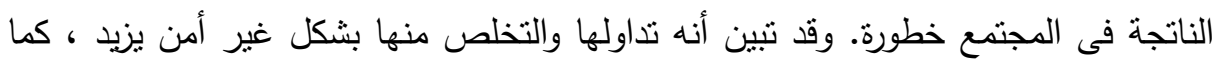

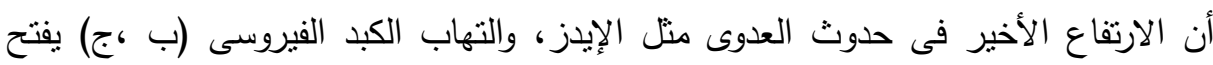

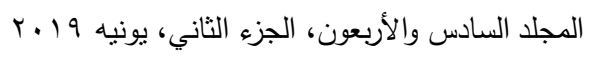


احتمال انتقال العدوى للاشخاص الذين يتعاملون مع هذه النفايات بالاضافة إلى المخاطر على

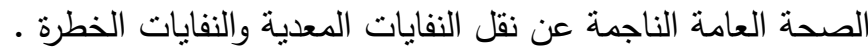
لذلك فقد قامت العديد من البلدان بوضع معايير ومواصفات واشتراطات خاصة بالتعامل

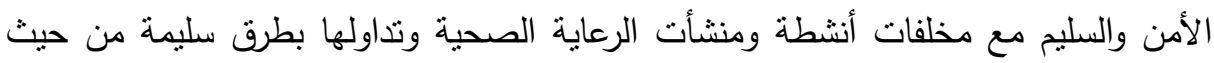

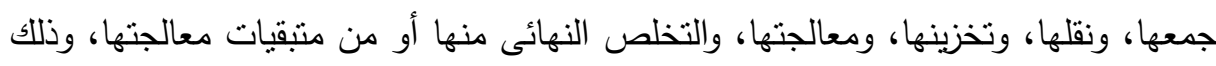
بهدف حماية الصحة العامة والبيئة المحيطة، ومنها التلوث البيئى وهذا يعتبر تحدى جديد حيث انه يحتاج الى كثير من التوعية والتوجيه أثثاء كافة مراحل وعمليات نداول تلاك

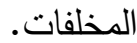

ومن هنا برزت أهمية إدارة منظومة الإدارة الأمنة والسليمة والمستدامة للنفايات الطبية بهدف التعامل الأمن مع المخلفات الطبية فى الأنشطة والمنشأت التى تقدم الرعاية الصحية الصنا

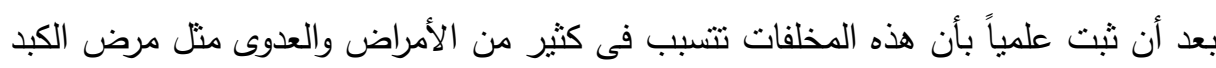
الوائى ( ب و ج ) والايدز والدرن (السل) إضافة إلى تأثنير هذه المخلفات على بلى برامج مكافحة العدوى فى المنشأت والمرافق الصحية كما ان التخلص منها بطريقة عشوائية يؤثر نأثيرا سلبيا

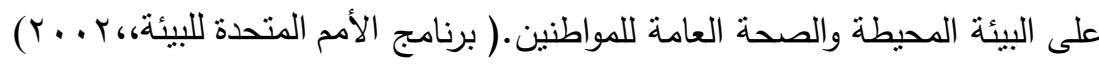

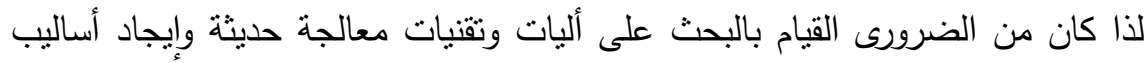

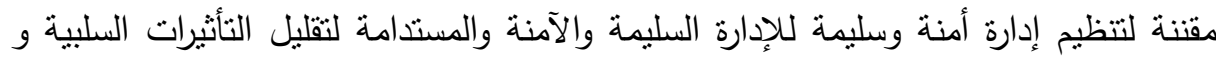
التخلص من الكميات الهائلة لتلك المخلفات بطريقة علمية وبتكلفة اقتصادية بحيث تقلل الأضرار الصحية والبيئية والاجتماعية لأدنى حد ممكن.

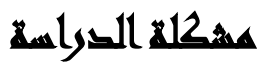

أصبحت مشكلة المخلفات الطبية في الوقت الحاضر مشكلة عالمية مشتركة بين جميع

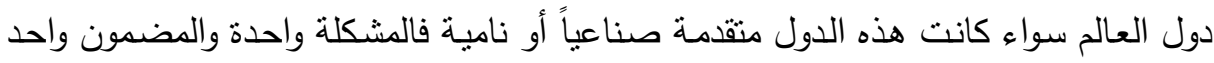

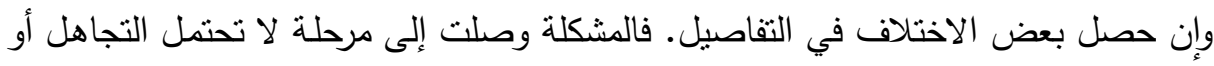

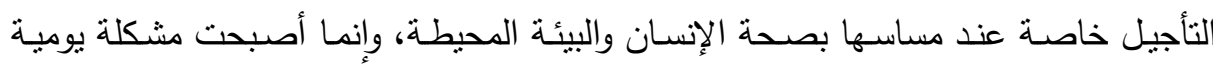

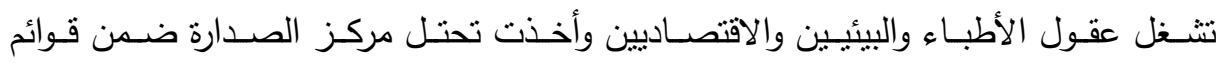


الأولويات للدول من حيث إيجاد الحلول العلمية والجذرية والسريعة لها.( عبد السـلام محمد

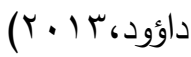

ويقوم البحث علي دراسة وتقييم مشكلة سوء إدارة مخلفات الرعاية الطبية والتي يواجهها المجتمع المصرى بصفة عامة وخاصة في المحافظات الأكثر كثافة من خلال دراسة تفصيلية

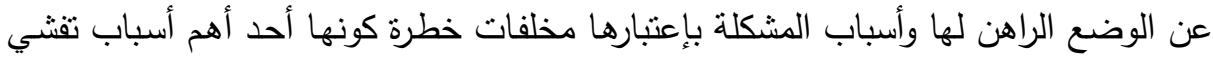

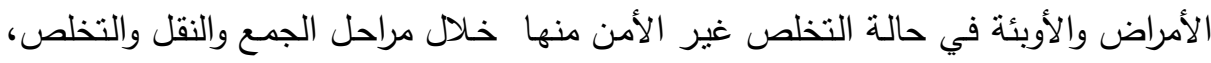
بالإضافة إلي إستغلال بعض العاملين ضعف الرقابة في مجال نقل المخلفات والتخلص منها ولإستغلالها في إعادة تصنيعها لإنتاج منتجات بلاسنيكية ولعب أطفال ومستلزمات غذائية وهو

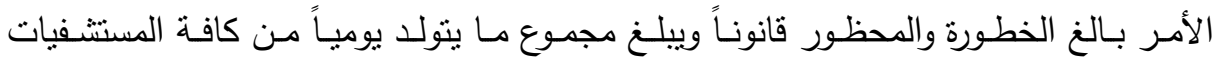

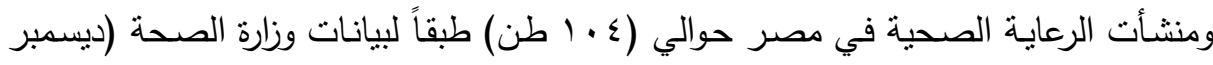

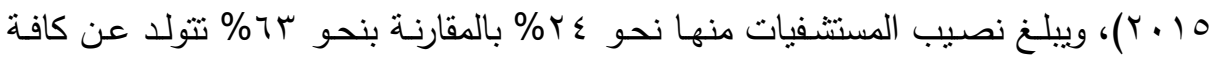

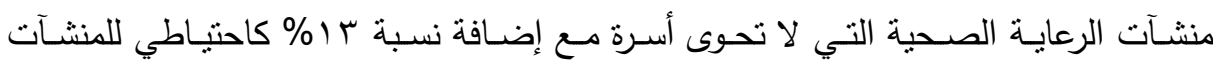
الصحية غير المسجلة. مما سبق ذكره، يمكن حصر إثكالية البحث في التساؤل الرئيسي الآتى:

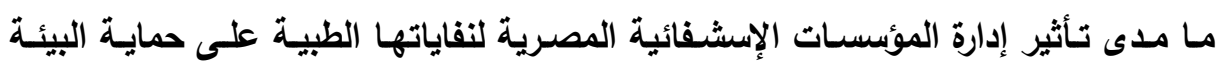
تقودنا هذه الإثكالية إلى طرح أسئلة الدراسة: تقودنا هذه الإشكالية إلى طرح التساؤلات الفرعية التالية: - ما أهم إنعكاسات النفايات الطبية على البيئة؟ الإنكانه - ماهي التقنيات المثلى لمعالجة النفايات الطبية؟ ماتج - ما هي ضوابط إدارة النفايات الطبية؟ - كيف تتم إدارة النفايات الطبية في المؤسسات الإسشفائية فى محافظات القاهرة الكبرى؟ 


\section{هزوضر الصواسما}

- - هناك فروق بين( المستشفيات الحكومية والجامعية وتتمية المتمع والخاصة) في مراحل جمع ونقل وتخزين ومعالجة والنقل الخارجي للنفايات والتدريب على التخلص من النفايات

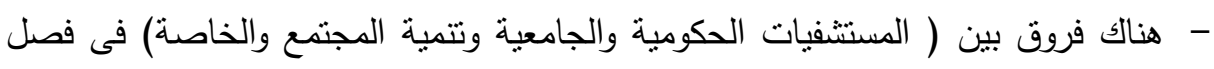

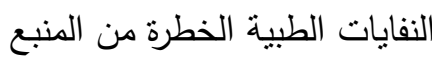
- - هناك فروق بين ( المستثفيات الحكومية والجامعية وتتمية المجتمع والخاصة) فى معالجة النفايات الطبية الخطرة منفصلة عن البلدية / العادية - هنالك فروق بين( المسنتفيات الحكومية والجامعية وتتمية المجتمع والخاصة) فى نقل

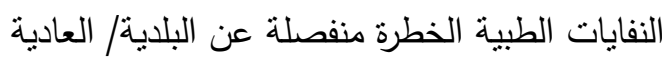
- - هناك فروق بين( المستشفيات الحكومية والجامعية وتتمية المجتمع والخاصة ) فى معالجة الجهات كمية النفايات الطبية المتولدة يومياً

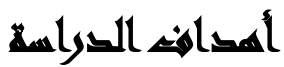

الهاف الرئيسي للبحث هو تقويم منظومة إدارة المخلفات الطبية الخطرة في محافظات القاهزة الكبرى لحل مشكلة تسرب المخلفات الطبية الخطرة إلى متعهذى القمامة الذين يقوم بعضهم بإعادة تدويرها لتصنيع المنتجات البلاستيكية ولعب الاطفال والمستلزمات الغذائية

وقد تفرع من هذا الهدف الرئيسي عدد من الأهداف الفرعية وهى كالتالى: 1-حصر مخلفات منشآت الرعاية الصحية في محافظات القاهرة الكبرى وأخطارها. r- التعرف على التباين المكاني والزماني في حجم المخلفات الطبية. r- تحليل الأساليب المتبعة في جمع وفرز ونقل المخلفات الطبية على مستوى القاهرة الكبرى. ع- دراسة الآثار الصحية والبيئية لمنظومة المخلفات الطبية على المجتمع المدني بالقاهرة الكبرى. 
0- وضع حلول عاجلة وأخرى آجلة ومخطط عام لمنظومة إدارة مخلفات أنشطة ومنشآت

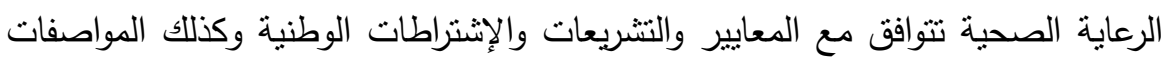

$$
\text { والمعايير الدولية. }
$$

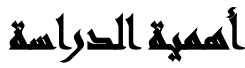

نظراً لخطورة مخلفات منشآت الرعاية الصحية كنفايات صحية خطرة طبقا لقانون البيئة

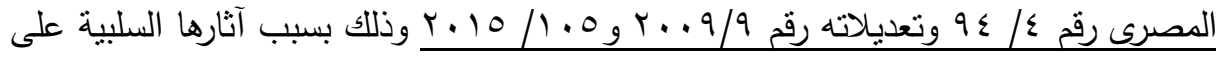
العاملين في المؤسسات الصحية والمجتمع والصحة العامة إن لم تتم إدارتها بشكل سليم، فهنالك العديد من الأمراض الخطيرة التي يمكن أن تتنقل عن طريق المخلفات مثل التهاب

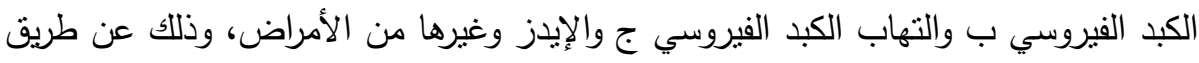
التعرض للعدوى من المعدات الملوثة الحادة منل الإبر الملوثة بدم المرضى الحاملين لمثل هذه منه

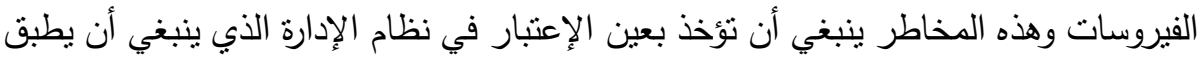

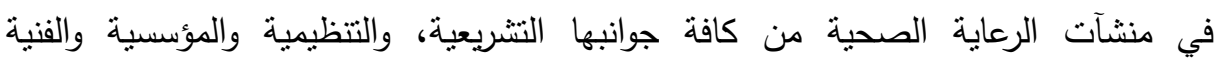
والتمويلية وكذا السلامة والصحة المهنية والتوعوية ومعظم هذه المخاطر موجودة في

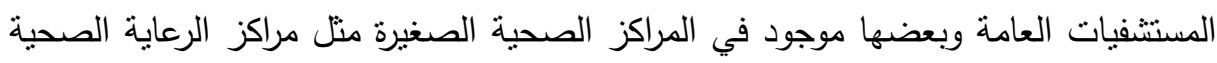

$$
\text { الأولية، والمختبرات الطبية، وعيادات الأسنان وغيرها. }
$$

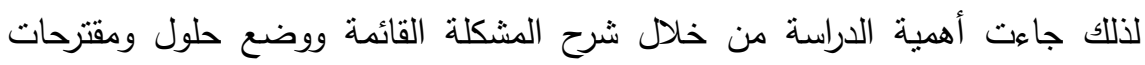
بهدف حماية المواطن المصرى والأطفال وكبار السن من انتشار الأمراض والأوبئة.

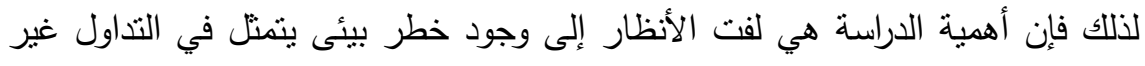

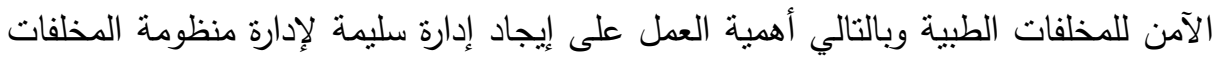




\section{هبوض الفواسم}

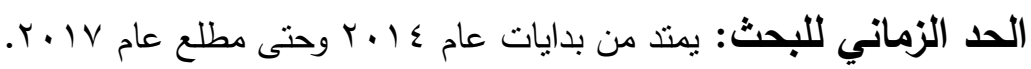
الحد المكاني: تكثف دراسة البحث على القطاع الطبي لتقويم منظومة المخلفات الطبية بمحافظات القاهرة الكبرى (القاهرة ـ الجيزة - القليوبية).

\section{منهمج التراسلة}

سـوف يطبق أسـلوب العرض التحليلي مستعيناً في ذلك بالكتب والدوريات والرسـائل العلمية ذات العلاقـة المباشـرة بمنظومـة إدراة المخلفات الطبية الخطرة في محافظـات القاهرة الكبرى تتقلت الدراسة بين العديد من المناهج الدراسية، حيث تتاول كل منهج منها موضوع خاص في الدراسة. يمكن توضيحها على النحو التالي: 1- المنهج التحليلى: تستخدم الباحثة المنهج التحليلى في تحليل الاستبيان الذي سيوزع على

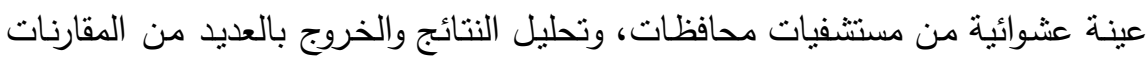
والتحليلات التي توضحح العلاقات حول المخلفات الطبية الخطرة.

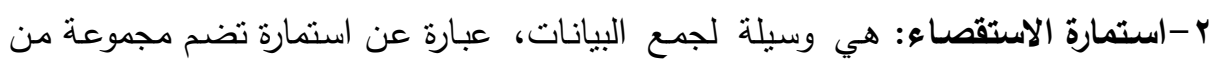

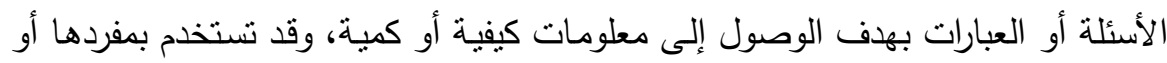
قد تستخدم مع غيرها من أدوات البحث العلمى الأخرى. وسوف ينم تصميم استمارة للبحث لجمع البيانات المطلوبة، حيث تنتاول جميع المحاور التي اشتملت عليها الدراسة. وتوزع الاستمارة على عينة البحث (مجتمع الدراسة)، حيث يتم اختيار عينة عشوائية من

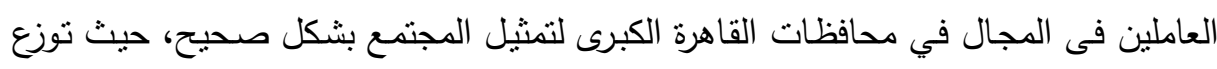
عينة أولية من الاستبانة لقياس ثبات الاستبيان، ودقة المعلومات. 
ب-نـوع البحث (مقارن): تستهدف الدراسات المقارنة الى تقرير خصائص ظاهرة معينة عبر

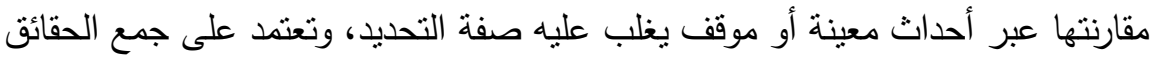
وتحليلها وتفسيرها لاستخلاص دلالتها وتصل عن طريق ذلك إلى إصدار تعميمات بشأن إنهات الموقف أو الظاهرة المدروسة.

المستفيدين من الدراسة: نقييم الوضع الراهن لإدارة منظومة المخلفات من خلال تطبيق

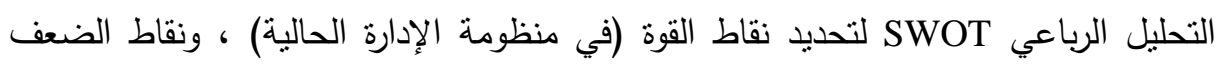
(الخلل الموجود في منظومة الإدارة ، والفرص المتاحة (الإستفادة من المخلفات في إنتاج قيم مضافة للتخلص من النفايات وتحويلها إلي طاقة) وكذلك التهديدات بهدف تقييم مخرجات التحليل الرباعي لوضع خطة تتمي نقاط القوة وتعالج نقاط الضعف وتستتمر الفرص وتتلافي التهديدات من خلال إقتراح منظومة معدلة لإدارة المخلفات الطبية الخطرة فى نطاق الدراسة.

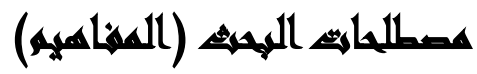

مخلفات منشآت الرعاية الصحية (النفايات الطبية): تعد النفايات الطبية مصدر يهدد حياة الكثيرين وخلال القرن الماضي ازداد مستوى العناية الصحية في المجتمعات فنرى في كل

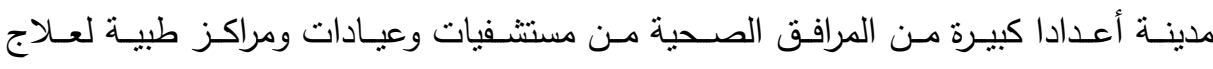
الأمراض، يتعاملون مع أعداد كبيرة من المرضى والمترددين وبسبب كل هذه الأنشطة تتتج

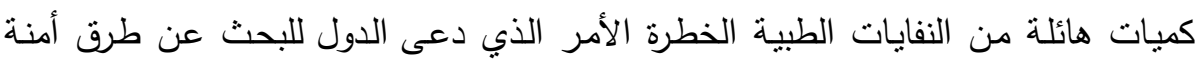

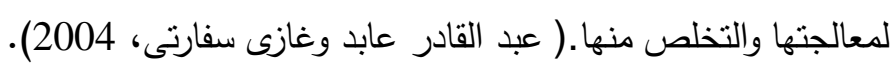
مصطلح" النفايات الطبية " أو" نفايات منشآت الرعاية الصحية " يشير إلى كافة النفايات التي تتنجها مرافق الرعاية الصحية. وهي تتمل النفايات التي تخلفها ممارسات طبية أو أنشطة تتصل بها والمصادر الرئيسية لهذه النفايات هي المستتفيات والمستوصفات والمختبرات وبنوك الدم ومشارح الموتى، في حين تُخلف عيادات الأطباء والأسنان والصيدليات قدرًا أقل من النفايات الطبية. (منظمة الصحة العالمية، 2004). 
وهى جميع النفايات الناتجة من المؤسسات الصحية مثل المستشفيات والمراكز الصحية

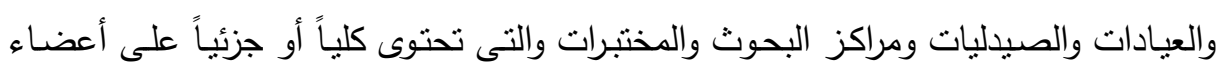

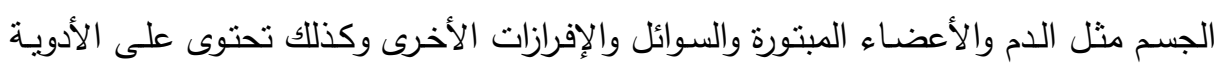

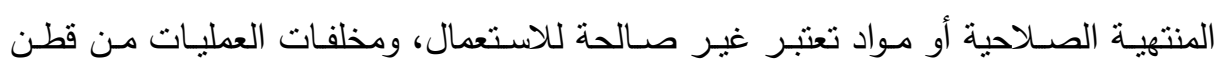

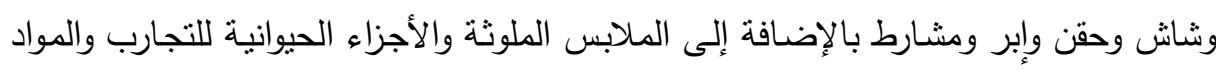

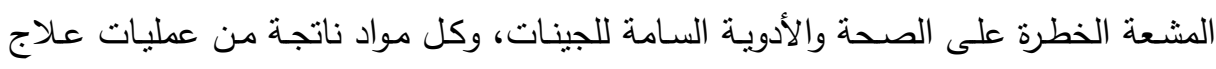
المرضـى ويرجى التخلص منها تعتبر نفايـات طبيـة ـ (منظمـة الصـحة العالميـة، 2002).

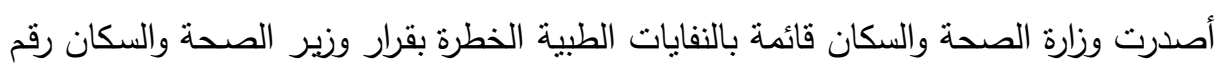

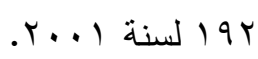

\section{تعريف النفايات الطبية:}

-هى النفايات التى تتتج من مصادر ملوثة أو محتمل نلوثها بالعوامل المعدية أو الكيمائية أو

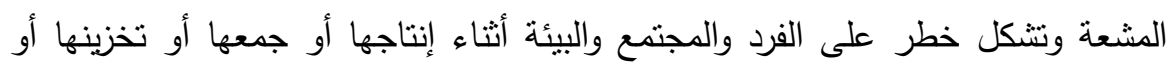

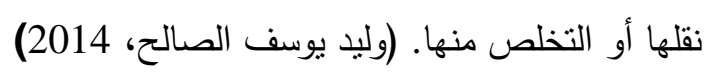

- هى مخلفات تتنج عن منشأة معالجة طبية، ويشمل ذلك المستشفيات والمختبرات الطبية

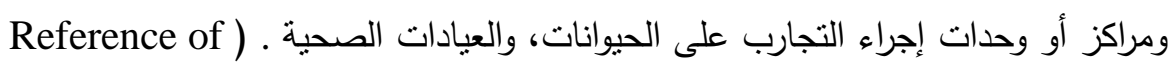

(2016 ، United states

-هي مواد بمكن أن يؤدي استعمالها بحسب الكمية أو التركيز أو الخواص الكيميائية والفيزيائية إلى الثأثير على الصحة العامة، أو زيادة نسبة الوفيات بين البشر و /أو التأثير

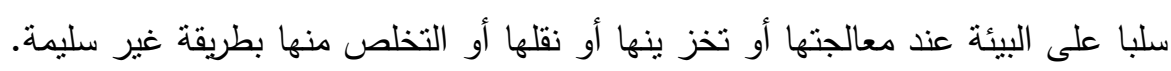

$$
\text { (سعد علي العنزي، 2012) }
$$


تصنيف النفايات الطبية: يمكن تلخيص تصنيف النفايات الطبية في الجدول الأتي:

\begin{tabular}{|c|c|}
\hline الوصف / الآمثنة & فَئَة النفايات \\
\hline 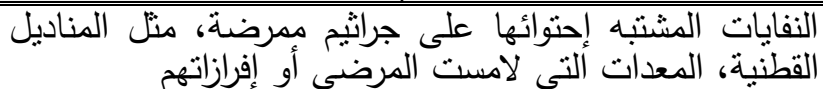 & المعدية \\
\hline الأخرى آنسجة أو السوائل البشرية، مثل أَجزاء الجسم، الدم أو السوائل & (النفايات الممرضة \\
\hline منل الإبر والمشارط . & 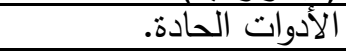 \\
\hline منل المواد الصبد لانية منتهية الصلاحية ، عبواتها وصناديقها. & النفايات الصيد لانية \\
\hline علاج السرطان النقية على بقايا عقاقير سمية ( تستخدم عادة فى & النفايات السا مة للجينات. \\
\hline متل مطهر الأفلام ، المطهرات والمذيبات . & النفابات الكيميائبة. \\
\hline الدم، أسطوأنات غاز التخدير الحرارة التالفة ، أجهزة قياس ضغط & العالتيات ذن المعادن الثقتيلة \\
\hline 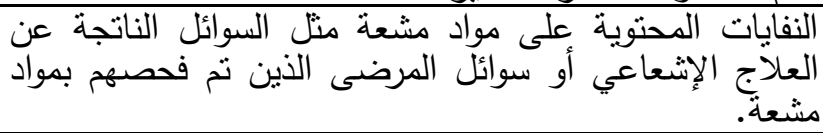 & النفايات المشعة. \\
\hline
\end{tabular}

المصدر: (تقرير منظمة الصحة العالمية، 2006)

مصادر النفايات الطبية: يمكن تصنيف مصادر النفايات الطبية إلى رئيسية وثانوية وفقاً لحجم

الكميات المنتجة كما هو موضح بالجدول الأتى:

\begin{tabular}{|c|c|}
\hline المصادر الثانوية & المصادر الرئيسية \\
\hline مؤسسات الرعاية الصحية الصغيرة ( العيادات ) & المستشفيات \\
\hline مؤسسات الرعاية الصحية المتخصصة ذات الإنتاج & متل العيادات الخارية الصحية الأخرى \\
\hline المنخفض للنفايات ( مستشفيات الرعاية النفسية ) . & المختبرات ومراكز الأبحاث . \\
\hline الأنشطة غير الصحية التى تشمل إدخالا وريديا أو تحت & مراكز التشريح ومستودع الجثث. \\
\hline جلد ( دور التجمبل أُو الوشم) & أبحاث وفحص الحيوان. \\
\hline دور خدمات الجنائز. & بنوك الدم وخدمات جمع الدم. \\
\hline العلاج المنزلي . & دور التمريض لكبار السن. \\
\hline
\end{tabular}

المصدر: (تقرير منظمة الصحة العالمية، 2006)

قدمت العديد من المسوحات الميدانية نتائج دراسات تبين أن إنتاج النفايات الطبية من

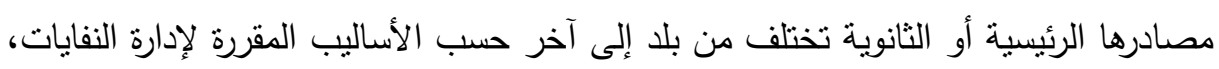

نوع المنشأة وعدد المرضى، ويتم قياسها بالترتيب: - حسب الإقليم أو الدولة وتقاس بالكيلوغرام على عدد السكان؛ 
-حسب المنشأة وتقاس بالكيلوغرام على عدد الأسرة؛ (دليل منظمة الصحة العالمبة، 2006)

الإتفاقيات الاولية المتعلقة بالنفايات الطبية:

التفاعلات الدولية جراء تفاقم مخاطر النفايات الطبية أفرز إتفاقيات دولية تنظر لطرق الإنهاتهات الإدارة الأمنة للنفايات الطبية، من بين هذه الإتفاقيات: ( عصام الحناوى، 2015)

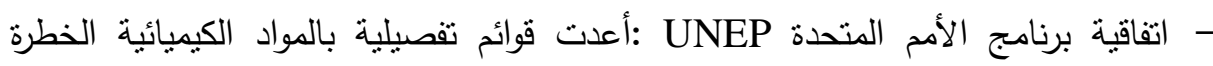
وخصائصها؛

ILO ومنظمة العمل الدولية: UNEP اتفاقية التعاون المشترك بين برنامج الأمم المتحدة: ومنظمة الصحة - العالميةWHO : رسمت أنسب الطرق لتداول المواد الكيميائية؛ - اتفاقية ستوكهولم: تهدف للقضاء أو الحد من استخدام الملوثات العضوية المقاومة للتحلل، بِهدف ضبط الاتجاه العام لمعالجة النفايات الطبية الخطرة رسمت جل الإتفاقيات المبادئ الأتي ذكرها: (Reference of the International ، • مبدأ الملوث يدفع Polluter pays : يتضمن أن جميع منتجي النفايات مسؤولون

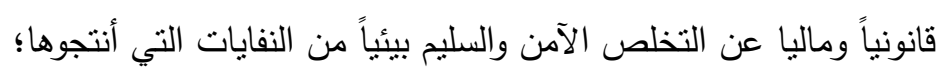

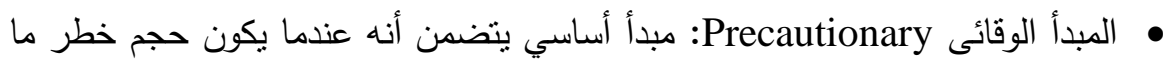
غير محدد يجب أن نفترض أن الخطر كبير، ويجب تصميم إجراءات حماية الصحة والسلامة وفقا لذلك؛ • مبدأ واجب العناية Duty of care: يشترط على أي شخص يتعامل مع أو يدير مواد

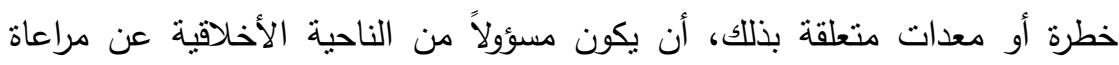
العناية القصوى في هذه المهام؛ • مبدأ القرب Proximity: يوصي بأن تتم معالجة النفايات الخطرة داخل الحدود الإقليمية للاولة وفي أقرب موقع مدكن تقليلاً لأخطار نقلها؛

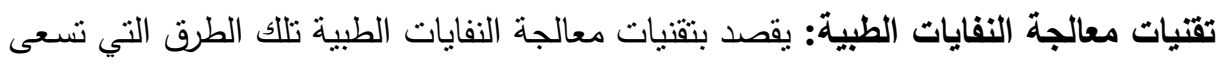

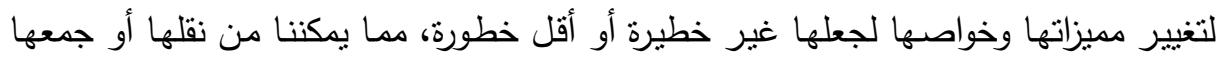
أو تخزينها أو التخلص منها دون أن تسبب أضراراً للأشخاص والبيئة. (برنامج الأمم المتحدة 


$$
\begin{aligned}
& \text { إن اعتماد إحدى هذه الطرق يتم علي الاعتبارات التالية: } \\
& \text { - تصنيف النفايات وطبيعة الخطر الذي تتطوي عليها؛ } \\
& \text { - التأثيرات الضارة المحنملة للنفايات الخطرة على البيئة؛ } \\
& \text { - - سهولة وموثوقية طريقة التخلص النهائي؛ } \\
& \text { - تكاليف التخلص النهائي وغيرها من التكاليف؛ }
\end{aligned}
$$

- - التأثير العام للمعمل أو معدات التخلص أو التصريف على البيئة المحلية والعامة.

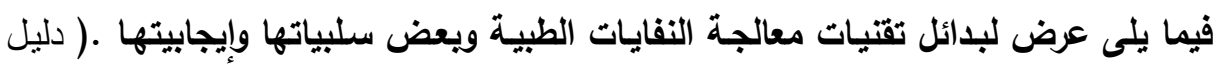

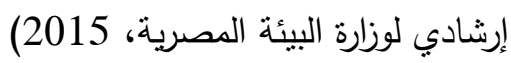

- المعالجة الحرارية للنفايات الطبية: تقنيات تتتهي بالتخلص النهائي من الرماد والمتنقيات في أو حفر مطامر آمنة تقع خارج المنشأة الصحية، تتمثل في:

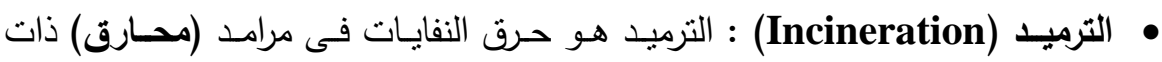
مواصفات صديقة للبيئة ، لكى تتحول إلى رماد؛ • التعقيم الكيمـاوي (Chemical Sterilisation): يتم تعريض النفايات للعناصر

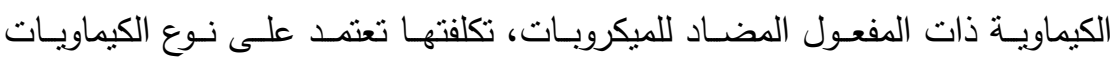
المستعملة، فقط تتطلب فنيين ذو خبرة عالية، وتتطلب مقاييس ومعايير كبيرة للوقاية

$$
\text { من أضرارها على الأفراد والبيئة. }
$$

• المعالجة الأرضية للنفايات الطبية الخطرة: تؤدى عملية المعالجة الأرضية للنفايات الطبية الخطرة المحتوية على مواد عضوية إلى تحلل الميكروبات والكائنات الحية الدقيقة هوائياً ولا هوائياً، وذلك بسبب توافئ لمراد المادة العضوية والسوائل بالنفايات، وتتم

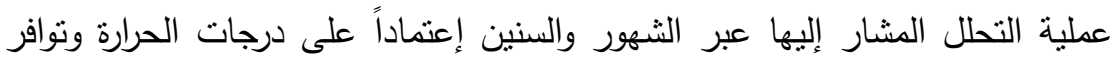
الهواء والماء. 
تتبعث من عملية المعالجة الأرضية للنفايات الطبية غير المعالجة روائح كريهة إلى ثلى تدائ

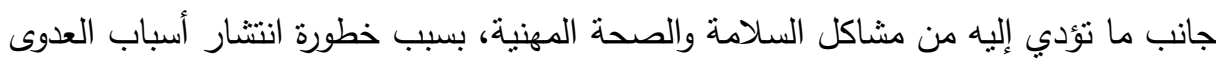

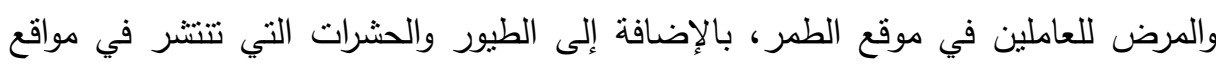
طمر ( دفن) النفايات.

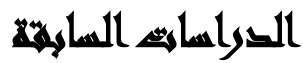

بعد المسح المكتبي لمختلف المراجع والمصادر المتعلقة بموضوع تقويم منظومة إدارة

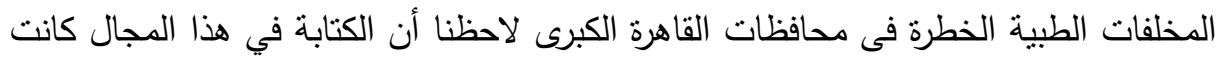

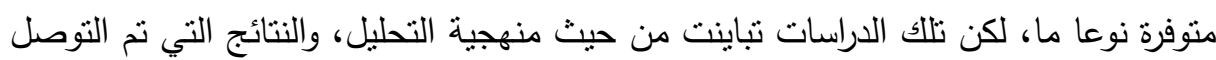

$$
\text { إليها. وفيما يلي نشير إلى أهم الدراسات التي تمكنا من الإطلاع عليها: }
$$

ا-دراسة عبد السالم محمد داؤود 2013، إدارة النفايات الطبية في مستثفيات مدينة شندي: وهدفت هذه الدراسة إلى تقييم إدارة النفايات الطبية في مستشفيات المدينة من حيث عملية الجمع، التخزين، النقل، التخلص النهائي ومعرفة مكونات إدارة النفايات الطبية بشكل خاص في المستشفى ودور البلدية في ذلك ومعرفة كمية النفايات المنتجة ونوعيتها والمشاكل الناتجة عنها، وأخيرا اقتراح توصيات لتحسين لتحسين الوضع القائم وتوصلت الدراسة إلى عدة نتائج أهمها: • • • ضرورة توفير البنية الأساسية اللازمة لإدارة النفايات الطبية في المستشفيات؛

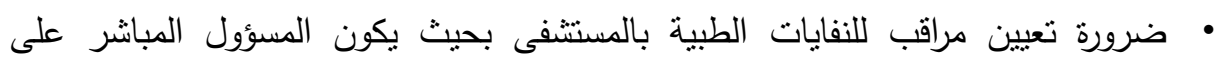

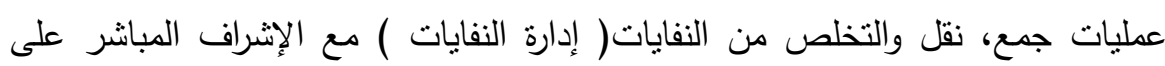
عمال النظافة بالمستشفى؛ • القيام بالتفتيش الصحي والرقابة على النفايات الطبية في المستشفيات، مع دراسة إمكانية تطبيق الأدوات الإقتصادية في مجال إدارة النفايات الطبية. 
ץ- دراسة رشا صلاح مهاى، 2014: كفاءة محارق النفايات الطبية فى مستثفيات الحلة فه_محافظة بابل : هدفت هذه الدراسة لفت الأنظار الى وجود خطر بيئى اسمه

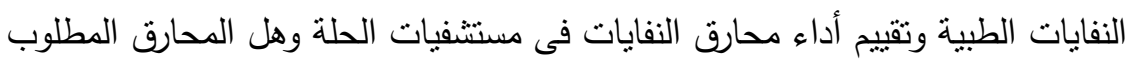

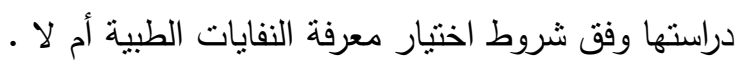
وتوصلت الاراسة إلى عدة نتائج أهمها: أ- إن أكثر معدلات تولد للنفايات وأقل كفاءة للإحتراق هى مستثنفى الحلة التعليمى فى مدينة الحلة وأعلى كفاءة للإحتراق هي محارق كل من مستشفى مرجان ومستشفى الولادة والأطفال

ب- أن هنالك حالات تجاوز على بيئة الددينة من خلال إلقاء بعض النفايات الطبية.

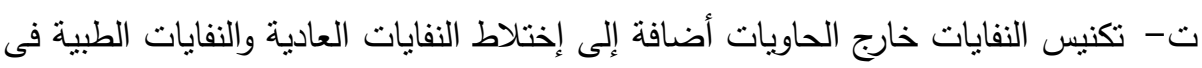
بعض المستثفيات. د- وجود محارق نفايات عاطلة عن العمل كما فى مستشفى الحلة التعليمى ومستشفى الولادة والأطفال مما يعرقل عملية حرق النفايات والتخلص الأمن منها.

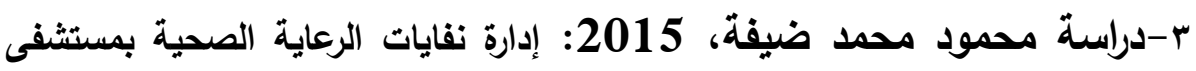

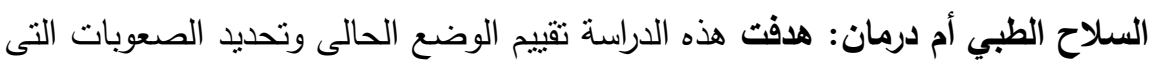

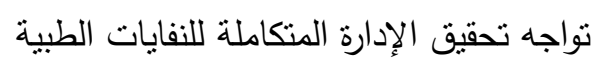
وتوصلت الدراسة إلى عدة نتائج أهمها: • أن مستثفى السلاح الطبى من أكثر المؤسسات الصحية فى البلاد تنتج النفايات الطبية

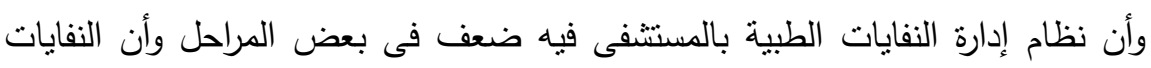
الطبية يتم نقلها والنخلص منها مع النفايات العادية ولا يوجد سجلات بكميات النفات النايات • • ل ايوجد تتسيق بين إدارة النفايات ومستوى التدريب الموجود 
(Nightingale institute for health environment (HCWM- 1 ، 2005)

بعنوان الإبداع فى معالجة النفايات الطبية بالمستثفيات، تناولت هذه الاراسـة ملاحظات Holie (Mcrea Glenn \& Shaner الولايات المتحدة، التي سجلوها من خلال عملهم في دول عديدة مثل أمريكا، الهند، نيوزلندا وجزر الكاريبي، حيث اكتشفت وجود خلل كبير في عمليات إدارة النفايات الطبية في هذه هنه البلدان، تمنلت في عدم إتباع السياقات الآمنة في التعامل مـع الخطر منها.

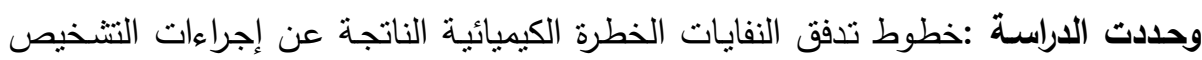
والعلاج والبحوث في المستشفيات، بهدف التعرف على المشكلات ومواقع الخلل . حiإ

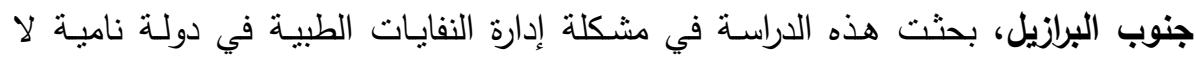

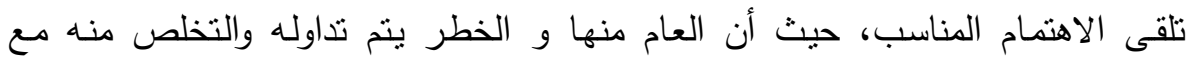
النفايات المنزلية الأخرى، ولذلك تسبب مخاطر صحية كبيرة لعامة الناس البيئة للعاملين بالبلديات، وقد قيمت في هذه الدراسة النفايات الطبية فى ( 91 ) منظمة صحية مجزئة على صلى (21) مستشفى و (47) مركز صحى و (23) مختبر سريرى، وأخرى مسح لجمع معلومات حول إدارة وعزل وتولد ومخزن للتخلص من النفايات الطبية. وأفادت الدراسة: أن إدارة النفايات الطبية بمعظم هذه ودز المنظمات لا يتماشى مع التشريعات القانونية في البرازيل، لكنها تقوم وبشكل صحيح بعزل النفايات المعدية.

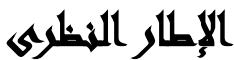

1-مفهوم إدارة النفايات الطبية وأهدافها. (دليل إرشادي لوزارة البيئة المصرية،ه 1 + ب) يقع على عاتق المستشفيات ومنشآت الرعاية الصحية الأخرى واجب الرعاية للبيئة والصحة العامة"، وعليها مسؤوليات خاصة فيما يتعلق بإدارة النفايات الصادرة عنها. r - تعريف إدارة النفايات الطبية: هي جزء من النظام الإداري البيئي الثامل الذي يمارس بادئ عملية مراقبة، جمع، نقل، معالجة، تدوير أو التخلص من النفايات الطبية. ( United :)(Nations, Department 
ب- أهداف إدارة النفايات الطبية:

الأهداف العامة لإدارة النفايات الطبية: (دليل منظمة الصحة العالمية، 2006): • التأكيد على الإدارة الجيدة للنفايات الطبية داخل المنشآت الصحية، ابتداء من فرز هذه الهاته النفايات في مصدرها، والتأكد من معالجتها، نهائي بما بضمن عدم نسببها في دائيات انتشار العدوى داخل المسنتفيات؛

• المحافظة على سالمة البيئة وحمايتها من التلوث وتوفير بيئة صحية سليمة بالمنشاة؛ • • تقييم تكاليف إدارة النفايات الطبية.

إن مؤتمر الأمم المتحدة للتنمية والبيئة (UNCED) المقام سنة 1992 أفضى إلى تبنى الأجندة 21 التي أوصت باستهداف مجموعة من النقاط، يمكن تلخيصها كما يلي:(فريد النجار ، 2014).

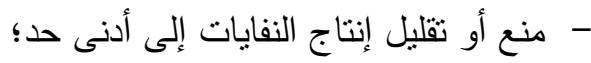
- معالجة النفايات بطرق آمنة وسليمة بيئيا؛

- التخلص من المتبقات النهائية لمعالجة النفايات بالطمر في مواقع محددة ومصمدة بعناية.

ع - الأسس الإستراتيجية لإدارة النفايات الطبية (المعه العربي لإنماء المدن،

$$
(r \cdot 17
$$

- دعم المنحى الوقائي في المنشآت الصحية في جميع الجوانب، بما في ذلك التخلص الأمن من النفايات الطبية الخطرة، وأخذ التدابير اللازمة للتعامل مع هذه النفايات في جميع مراحلها بالطرق العلمية المعروفة؛ من إتهات - - إدارة النفايات الطبية والتخلص منها بالسبل والوسائل المناسبة لتفادي تأثيرها على الصحة

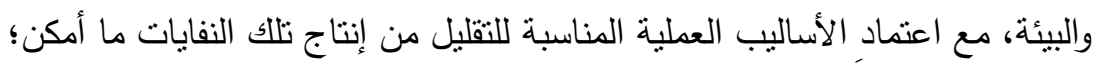

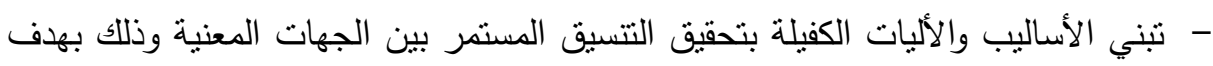
توحيد وتكامل الجهود بين الجهات ذات العالقة للتخلص من النفايات الطبية. 
ه-محدات إدارة النفايات الطبية: يقصد بمحددات إدارة النفايات الطبية تلك المحاور التي تدور حول مضمونها العملية الإدارية بما بضمن تحقيق هدفها وتطوير سلوكها

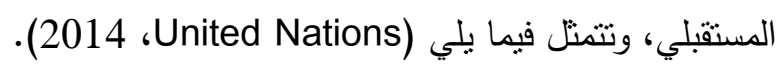

- ضرورة دراسة معمقة عن الوضعية وطرق تتفيذ العمل وتحديد كميات وأصناف النفايات؛

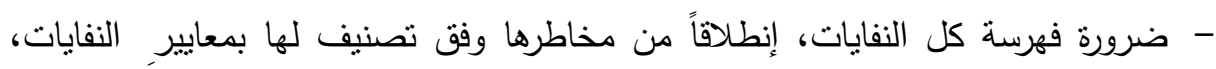
مجسدة؛

- اختيار مراحل التخلص المناسبة والموافقة لكل صنف من الأصناف المرنبة؛

- الإعتماد بطريقة ذات إمنياز على إمكانيات المعالجة الخارجية داخل المنشأة الصحية.

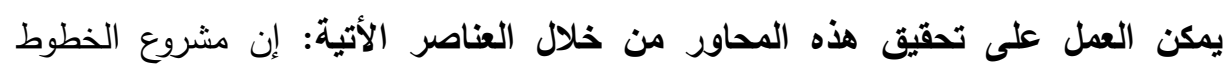

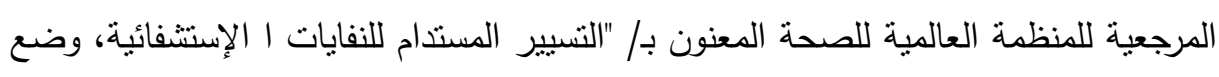
لإمكانية تحقيق: Rapport de l'Organisation) ، - توعية الأطراف المعنية حول ضرورة النسيير السليم للنفايات داخل المنشآت الصحية. - - وضع خطوط مرجعية لسياسات نظام التسيير وطرق معالجة النفايات والتقليل من حجمها. - تنظيم التكوين في مجال تسبير النفايات الطبية.

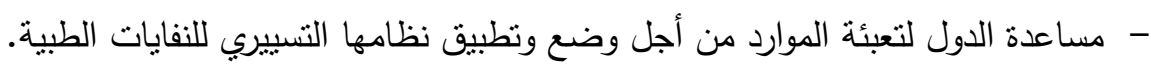

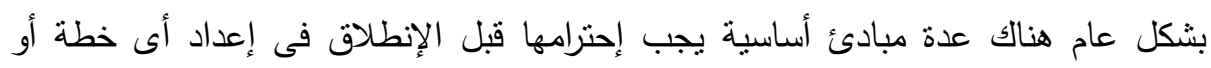
أطلاق أى برنامج لإدارة النفايات الطبية.

\section{إجراءايه التواسما}

مجتمع وعينة الدراسة: يتمثل مجتمع الدراسة فى تقديم المستشفيات الثلاثة (الحكومية -

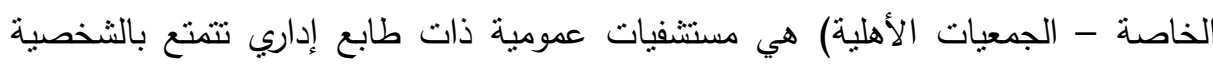
المعنوية والاستقلال المالى وتوضع تحت وصاية الدولة. عينة الدراسة: إذا كانت المستثفيات الثناثة فى محافظات القاهرة الكبرى مجنمعاً للبحث فقد

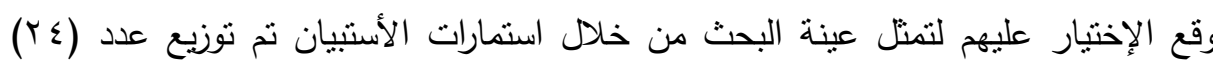
استمارة على مفردات مجتمع الدراسة. 


\section{أسوايت السواسما}

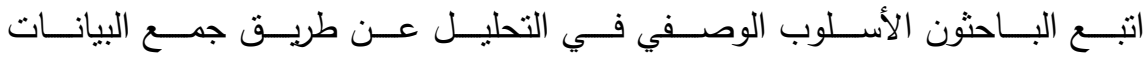

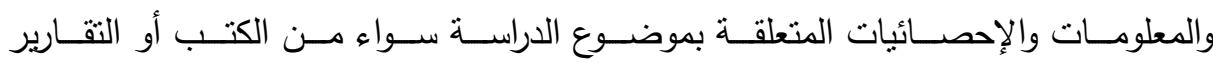

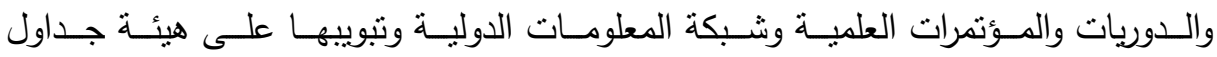

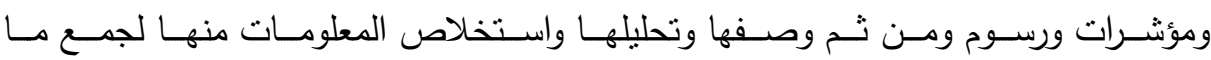
يخص طبيعة البحث من احصاءات ومنشورات. كما استخدم المنهج الإحصائي لإختيار أدوات القياس والتحقق من صحة الفروض بإنست إنتخدام

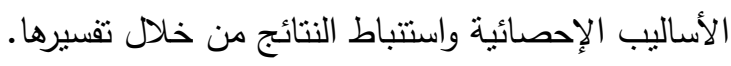
الدراسة العملية ومصادر البيانات: تشمل المرحلة الثانية للاراسة البحثية الدراسة المبدانية البهابة

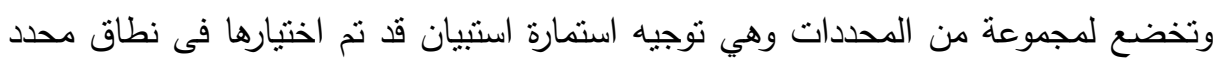
ثم إجراء مقابلات شخصية مع المبحوثين وهم: فقد تم ربط الاتصال بكل المنفذين أو المشرفين أو المراقبين لبرنامج إدارة النفايات الطبية بالمستشفيات الثلاثة سواء مدير المسنشفى، مدير السلامة والصحة المهنية، مدير الموارد

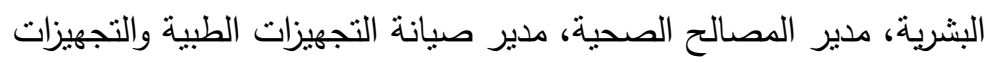
احتوت استمارات الاستبيان على اثثين وستون سؤال ثم تقسيمهم فى أربع مجموعات

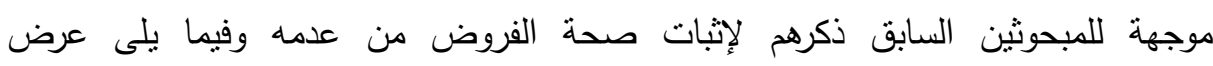
لمجموعات اسئلة استمارة الاستنيان: ا. هناك فروق بين (المستشفيات الحكومية والجامعية وتتمية المجتمع والخاصة) في مراحل جمع ونقل وتخزين ومعالجة والنقل الخارجي للنفايات والتدريب على التخلص من ولنية النفايات

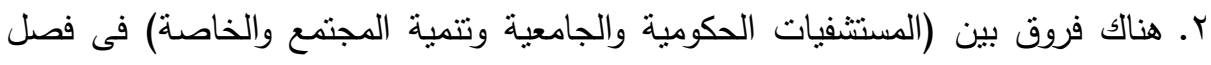

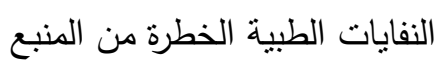
r. هناك فروق بين (المستشفيات الحكومية والجامعية وتتمية المجتمع والخاصة) فى معالجة النفايات الطبية الخطرة منفصلة عن البلدية / العادية

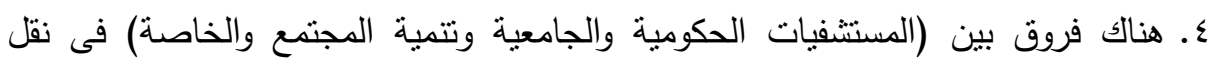

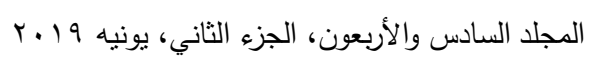




$$
\text { النفايات الطبية الخطرة منفصلة عن البلدية/ العادية }
$$

ه. هناك فروق بين (المستثفيات الحكومية والجامعية وتتمية المجتمع والخاصة ) فى معالجة كمية النفايات الطبية المنولدة يومياً

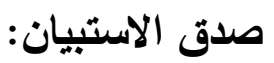
أولاً اختبار ثبات وصدق المقياس: اختبار الثبات: نم استخدام اختبار ألفا كرونباخ CronbachsAlpha لاختبار ثبات ابعاد التباد

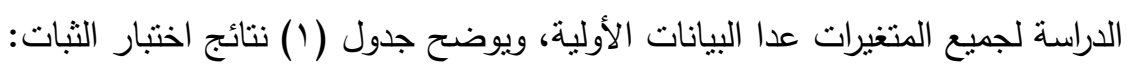
جدول ( ) : اختبار ثبات ألفا كرونباخ لاستبيان النفايات والمخلفات

\begin{tabular}{|c|c|c|}
\hline عدد العبارات & معامل اللفا & الابعاد \\
\hline T\& & $\cdot, \times 79$ & جمع النفايات \\
\hline$\pi$ & .,TYו & نقل النفايات \\
\hline$T \varepsilon$ & $\cdot, V \mu V$ & تخزبن النفابات \\
\hline$\pi$ & $\cdot$, , גדr & معالجة النفابات \\
\hline 17 & $\cdot, 70 \pi$ & النقل الخارجى للنفايات \\
\hline 10 & $\cdot, 791$ & التوعية والتذريب والتصحة والسلامة المهنية \\
\hline
\end{tabular}

المصدر: مخرجات البرنامج الاحصائى الئي

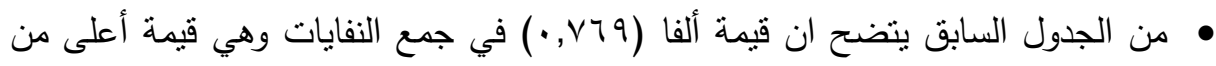

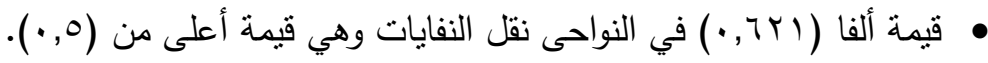

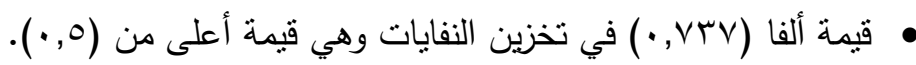

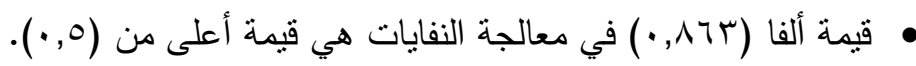

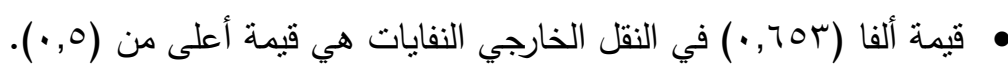

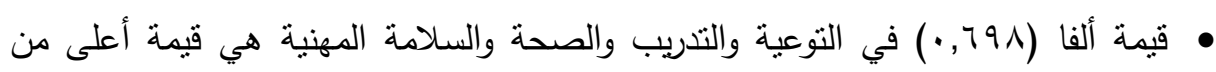
$\cdot(\cdot, 0)$

• وتدل مؤشرات ألفا كرونباخ أعلاه على تمتع أبعاد الاستبيان بمعامل ثابت عالٍ وبقدرتها على تحقيق أغراض الدراسة، ويمكن للباحثة نطبيقه على عينة الدراسة. 
صدق الاتساق الداخلي: ولمزيد من التحليل، فقد قامت الباحثة بحساب صدق الإتساق الداخلي

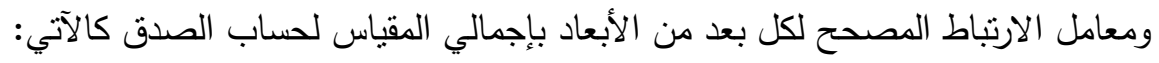

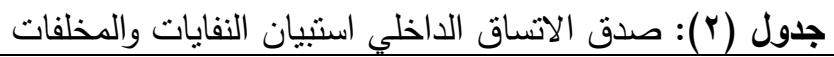

\begin{tabular}{|c|c|c|c|}
\hline معامل التصحيح & إجمالى المقياس & \multicolumn{2}{|c|}{ الأبعاد } \\
\hline \multirow{2}{*}{$\cdot, \vee_{0}$} & $\left({ }^{* * 2}\right), 7,7$ & معامل الارتناط & \multirow{2}{*}{ جمع النفايات } \\
\hline & $\cdot, \cdots 1$ & الدلالة المعنوية & \\
\hline \multirow{2}{*}{$\cdot, \vee \vee q$} & $\left({ }^{* *}\right) .701$ & معامل الارتباط & \multirow{2}{*}{ نقل النفايات } \\
\hline & $\cdot, \cdots 1$ & الدلالة المعنوية & \\
\hline \multirow{2}{*}{$\cdot, \wedge \Gamma$} & $(" *) \cdot, V \cdot T$ & معامل الارنباط & \multirow{2}{*}{ تخزين النفايات } \\
\hline & $\cdot, \cdots 1$ & الدلالة المعنوية & \\
\hline \multirow[t]{2}{*}{$\cdot, \wedge 7$} & $(* *),, \vee 0 \leq$ & معامل الارتباط & \multirow{2}{*}{ معالجة النفايات } \\
\hline & $\cdot, \cdots 1$ & الدلالة المعنوية & \\
\hline \multirow[t]{2}{*}{$\cdot, 10$} & $\left({ }^{* *}\right),, \vee \leq 0$ & معامل الارنباط & \multirow{2}{*}{ النقل الخارجي للنفايات } \\
\hline & $\cdot,, \cdots$, & الدلالة المعنوية & \\
\hline \multirow[t]{2}{*}{$\cdot, \wedge 0$} & $\left({ }^{* *}\right) \cdot, V M V$ & معامل الارتباط & \multirow{2}{*}{ لتوعية والتدريب والصحة المينة } \\
\hline & $\ldots 1$ & الد لالة المعنونة & \\
\hline
\end{tabular}

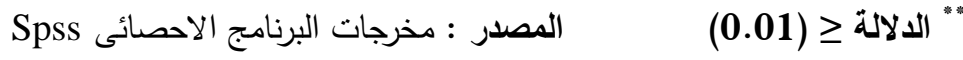

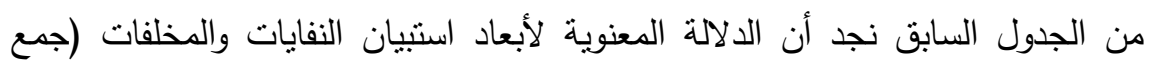

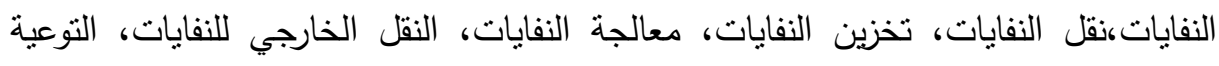

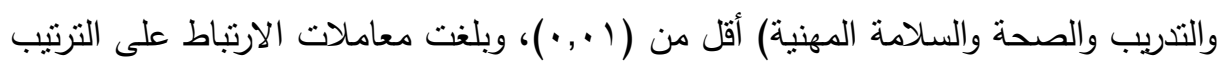

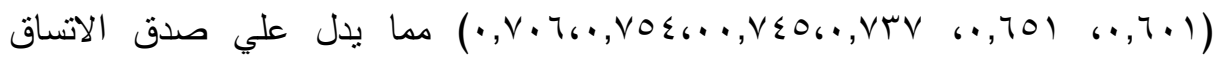

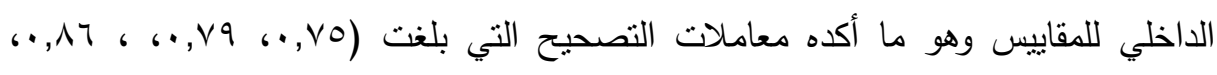

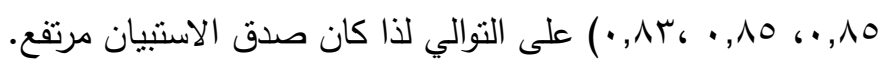
جدول (ץ): استعراض تبعية المستشفيات محل الدراسة

\begin{tabular}{|c|c|c|}
\hline نسبة \% & عدد & مستشفيات \\
\hline$\{0, \Lambda$ & 11 & وزارة الصحة أو هيئات ذات صلة بالوزارة \\
\hline$r \cdot, \Lambda$ & 0 & جامعية \\
\hline$\lambda, r$ & r & خيرية أو تتبع جمعية تتمية مجتمع \\
\hline ro & 7 & خاصة أو استثمارية \\
\hline $1 \ldots$ & $T \Sigma$ & مجموع ( مجوع \\
\hline
\end{tabular}

Spps المصدر : مخرجات البرنامج الاحصائى

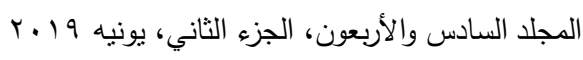


يوضح الجدول السابق ان المستشفيات التى تتبع وزارة الصحة أو هيئات ذات صلة

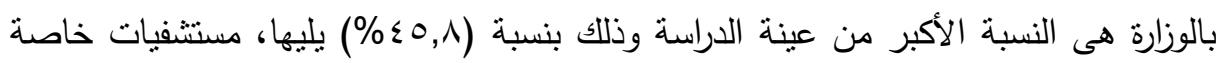

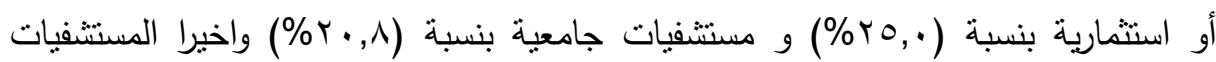

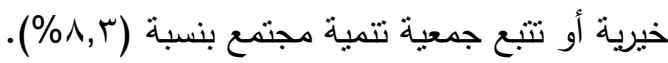

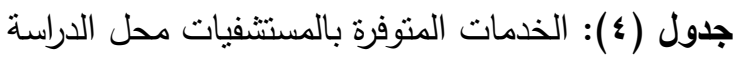

\begin{tabular}{|c|c|c|c|c|}
\hline متوسط +1. م- م & المدى (أقل - أعلى) & نسبة \% & عدد & الخدمات المتوفرة \\
\hline \multirow{4}{*}{ ror,q土mar, ro } & \multirow[b]{4}{*}{$\mid r \ldots-\varepsilon \Lambda$} & $r \cdot, \Lambda$ & 0 & أقل من الأسرة: .. \\
\hline & & $17, \mathrm{~V}$ & $\varepsilon$ & $199-1 \ldots$ \\
\hline & & $r \mu, r$ & $\Lambda$ & $\sum q 9-r \ldots$ \\
\hline & & $r q, r$ & $\mathrm{v}$ & . . . فأكثر \\
\hline \multirow{5}{*}{$\begin{array}{l} \pm 9 \vee 094, . . \\
\text { Iтqฯ }\end{array}$} & \multirow[b]{5}{*}{$T \cdot \Lambda, 0-\cdot, r$} & $r v, 0$ & 9 & متوسط عدد المرضى في (بالفف): \\
\hline & & $r v, 0$ & 9 & $9-1$ \\
\hline & & $17, \mathrm{~V}$ & $\varepsilon$ & $\leqslant 9-1$. \\
\hline & & & & $99-0$. \\
\hline & & $\Lambda, r$ & $r$ & 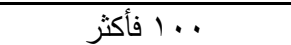 \\
\hline \multirow{3}{*}{$11, r 0 \pm 1 \cdot, r q$} & \multirow[b]{3}{*}{$7 \cdot-r$} & $r \cdot, \Lambda$ & 0 & عدد غرف العمليات: \\
\hline & & ro & 7 & $9-0$ \\
\hline & & $0 \leqslant, r$ & $1 \pi$ & ـ ـ فأكثر \\
\hline \multirow{3}{*}{$r, r \tau+r, v 0}$. & \multirow[b]{3}{*}{$1 \leqslant-1$} & $\{0, \Lambda$ & 11 & عدد المعامل(المختبرات): \\
\hline & & $r$ & $\Lambda$ & $7-\varepsilon$ \\
\hline & & $r \cdot, \Lambda$ & 0 & V V فأكثر V V V V V \\
\hline \multirow{4}{*}{$|7, \varepsilon 1 \pm| 7, r 9 \mid$} & \multirow[b]{4}{*}{ v. - . } & $\Lambda, r$ & $r$ & 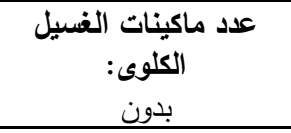 \\
\hline & & $\leq 0,9$ & 11 & $9-1$ \\
\hline & & $r v, 0$ & 9 & $r q-1$. \\
\hline & & $\Lambda, r$ & $r$ & 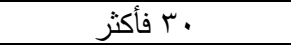 \\
\hline
\end{tabular}


مجلة العلوم البيئية

معهد الدراسات والبحوث البيئية - جامعة عين شمس به

تابع جدول (ء): الخدمات المتوفرة بالمستشفيات محل الدراسة

\begin{tabular}{|c|c|c|c|c|}
\hline متوسط +|!.م & $\begin{array}{c}\text { المدى (أقلى } \\
\text { أعلى) } \\
\end{array}$ & نسبة \% & عدد & الخدمات المتوفرة \\
\hline \multirow{4}{*}{$1 V, V \vee \pm 1 V, 0}$. & \multirow[b]{4}{*}{ r. - . } & $\Lambda, r$ & $r$ & عدد حضانات حديثى الولادة: \\
\hline & & $\Lambda, r$ & r & $\varepsilon-1$ \\
\hline & & $r q, r$ & $V$ & $9-0$ \\
\hline & & $0 \leqslant, Y$ & $1 \pi$ & • ا فأكثر \\
\hline \multirow{4}{*}{$r r, r q+r q, r q$} & \multirow[b]{4}{*}{$0 \leqslant-\varepsilon$} & 90,1 & r & عدد الأقتسام السريرية: \\
\hline & & $\varepsilon, Y$ & 1 & $9-0$ \\
\hline & & & & $r q-1$. \\
\hline & & & & •r فأكثز \\
\hline \multirow{3}{*}{$1 \leqslant, 0 \wedge+19,0 \leqslant$} & \multirow[b]{3}{*}{ ז. $-r$} & $1 r, 0$ & $r$ & $\begin{array}{c}\text { عدد العيادات الخارجية: } 1 \\
\text { - } 1\end{array}$ \\
\hline & & $\Lambda, r$ & $r$ & $9-0$ \\
\hline & & $\vee q, r$ & 19 & . أ فأكثز \\
\hline
\end{tabular}

المصدر : مخرجات البرنامج الاحصائى spps

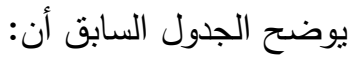

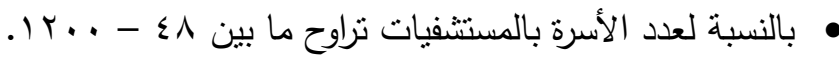

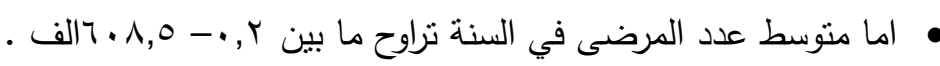

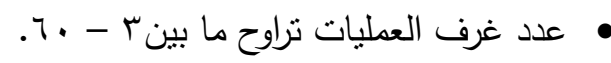

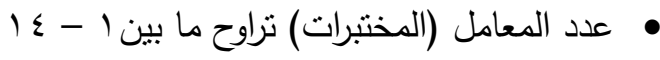

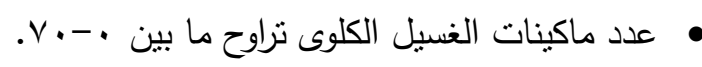

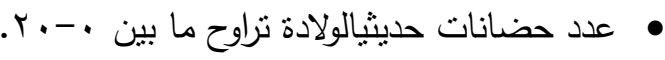

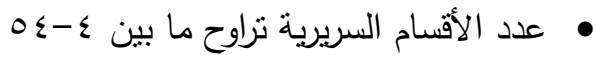

عدد العيادات الخارجيةتراوح ما بين ب - . . 
جدول(؛ 1): يوضح الفرق بين المستشفيات الحكومية والجامعية وتتمية المجتمع والخاصة في فصل النفايات الطبية الخطرة من المنبع

\begin{tabular}{|c|c|c|c|c|c|c|}
\hline 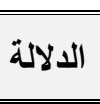 & قَّمة & انحراف & متوسط & العدد العد & نوع المستشفى & \\
\hline \multirow{4}{*}{ - } & \multirow{4}{*}{$\cdot$} & . & 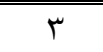 & 11 & مستشفيات وزارة الصحة & \multirow{4}{*}{ 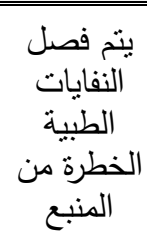 } \\
\hline & & . & $r$ & 0 & مستشفيات جامعية & \\
\hline & & . & r & $r$ & مستشفيات خيرية تتمية & \\
\hline & & . & $r$ & 7 & خاصة او استثمارية & \\
\hline
\end{tabular}

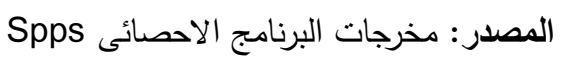

يوضح الجدول السابق أنه لا توجد فروق بين المستتفيات الحكومية والجامعية وتتمية

المجتمع والخاصة في فصل النفايات الطبية الخطرة من المنبع حيث كان إجابات المبحوثين

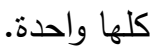

جدول(ه 1): يوضح الفرق بين المستشفيات الحكومية والجامعية وتتمية المجتمع والخاصة فييوجد داخل المستشفى وسيلة معالجة للنفايات الطبية الخطرة

\begin{tabular}{|c|c|c|c|c|c|c|}
\hline الدلالة & قيمة ف & معياري & متوسط & العدد العد & نوع المستثفى & \\
\hline \multirow{4}{*}{$\cdot, 9$} & \multirow{4}{*}{$\cdot, .9$} & $1, Y 0 \cdot \leqslant 0$ & 1,1 & 11 & مستشفيات وزارة & \multirow{4}{*}{ الطعالجتشفي للنفاياتِ دسلة } \\
\hline & & $\cdot, v \cdot v 11$ & 1 & 0 & مستشفيات جامعية & \\
\hline & & r,I TIM & 1,0 & r & مستشفية المجنميرية & \\
\hline & & 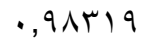 & 1,17 & 7 & خاصة او استثمارية & \\
\hline
\end{tabular}

Spps المصدر: مخرجات البرنامج الاحصائى

يوضح الجدول السابق انه لا نوجد فروق بين المستشفيات الحكومية والجامعية وتتمية المجتمع والخاصة في يوجد داخل المستشفى وسيلة معالجة للنفايات الطبية الخطرة حيث كانت قيمة الدلالة اكبر من (0. . •) وهى قيمة غير دالة إحصائيا. 
جدول (1 1 ): يوضح الفرق بين المستتفيات الحكومية والجامعية وتتمية المجتمع والخاصة

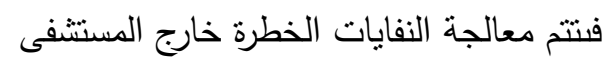

\begin{tabular}{|c|c|c|c|c|c|c|}
\hline 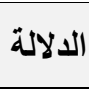 & قَيمة & معياري & متوسط & العدد & نوع المستثفى & \\
\hline \multirow{4}{*}{$\cdot r$} & \multirow{4}{*}{ 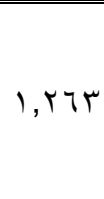 } & $1, \varepsilon \cdot 1 \pi$ & 1,1 & 11 & مستشفيات وزارة الصحة & \multirow{4}{*}{ التفايات الخطرة } \\
\hline & & $1, \Gamma \cdot r \wedge \varepsilon$ & $r, r$ & 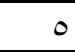 & مسنتشفيات جامعية & \\
\hline & & $\cdot, v \cdot V \| 1$ & 1,0 & $r$ & مستتفيات خيرية تتمية|لمجتمع & \\
\hline & & $1, Y Y \leqslant V \leqslant$ & $r, 0$ & 7 & خاصة او استثمارية & \\
\hline
\end{tabular}

المصدر: مخرجات البرنامج الاحصائى spps

وضح الجدول السابق انه لا توجد فروق بين المستثفيات الحكومية والجامعية وتتمية

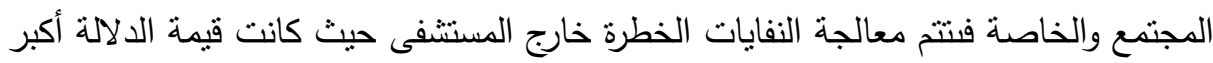
من (0. . • •) وهى قيمة غير دالة إحصائيا. جدول (IV): يوضح الفرق بين المستثفيات الحكومية والجامعية وتتمية المجتمع والخاصة فيبتم معالجة النفايات الطبية الخطرة منفصلة عن البلدية / العادية

\begin{tabular}{|c|c|c|c|c|c|c|}
\hline 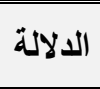 & قَيمة & معياري & متوسط & العدد & نوع المستثفى & \\
\hline \multirow{4}{*}{$\cdot, \mathrm{V}$} & \multirow{4}{*}{$\cdot, \Gamma \varepsilon$} & 1,01 rov & 1,9 & 11 & مستتنفيات وزارة الصحة & \multirow{4}{*}{ النفايات الطبية } \\
\hline & & $1, r \cdot r \Lambda \varepsilon$ & $r, r$ & 0 & مستشفيات جامعية & \\
\hline & & T,IYITK & 1,0 & $r$ & مستشفيات خيرية تتميةالمجتمع & \\
\hline & & $1, Y Y \leqslant V \leqslant$ & $r, 0$ & 7 & خاصة او استثمارية & \\
\hline
\end{tabular}

المصدر: مخرجات البرنامج الاحصائى spps

يوضح الجدول السابق انه لا نوجد فروق بين المستشفيات الحكومية والجامعية وتتمية

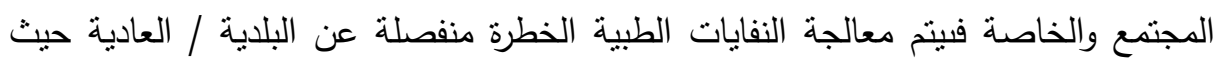
كانت قيمة الدلالة أكبر من (0. . • •) وهى قيمة غير دالة إحصائيا. 
جدول (1 1): يوضح الفرق بين المستشفيات الحكومية والجامعية وتتمية المجتمع والخاصة فيتت معالجة كمية النفايات الطبية المنولدة بومياً

\begin{tabular}{|c|c|c|c|c|c|c|}
\hline الالالة & قبمة & معياري & متوسط & 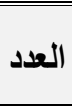 & نوع المستشفى & \\
\hline & & $1, \varepsilon V \cdot q r$ & $1, \wedge$ & 11 & مستشفيات وزارة الصحة & \multirow{4}{*}{ كيتم الطية النفايات } \\
\hline & & $1, \Gamma \cdot \Gamma \wedge \varepsilon$ & $r, r$ & 0 & مسنتفيات جامعية & \\
\hline & & r,IMITr & 1,0 & $r$ & مستشفيات خيرية تتمية المجتمع & \\
\hline • & $\cdot, r \wedge \neg$ & $1, Y 11 \cdot 7$ & $r, r$ & 7 & خاصة او استثمارية & \\
\hline
\end{tabular}

المصدر: مخرجات البرنامج الاحصائى spps

يوضح الجدول السابق إنه لا توجد فروق بين المستشفيات الحكومية والجامعية وتتمية

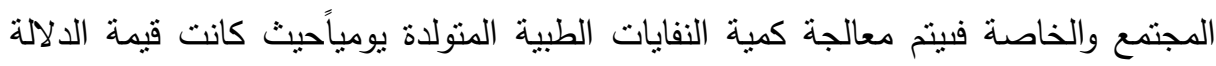

$$
\text { أكبر من (0 . • •) وهى قيمة غير دالة إحصائيا. }
$$

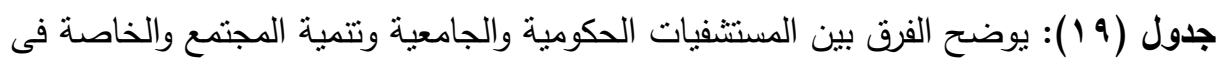
يتم نقل النفايات الطبية الخطرة منفصلة عن البلدية/ العادية لعنية

\begin{tabular}{|c|c|c|c|c|c|c|}
\hline الالالة & قيمة & معياري & متوسط & العدد الع & نوع المستشفى & \\
\hline \multirow{4}{*}{$\bullet$} & & - & r & 11 & مستشفيات وزارة الصحة & \multirow{4}{*}{ التفايات الطبية } \\
\hline & & . & $r$ & 0 & مسنتفيات جامعية & \\
\hline & & $\cdot$ & $r$ & $r$ & مستشفيات خيرية نتمية المجتمع & \\
\hline & & - & r & 7 & خاصة او استثمارية & \\
\hline
\end{tabular}

Spps المصدر : مخرجات البرنامج الاحصائى

يوضح الجدول السابق انه لا توجد فروق بين المستثفيات الحكومية والجامعية وتتمية

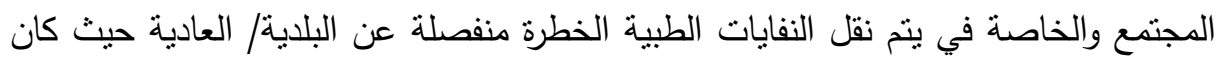
إجابات المبحوثين كلها واحدة. 
مجلة العلوم البيئية

معهد الدراسات والبحوث البيئية - جامعة عين شمس لكس

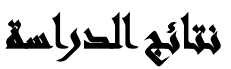

1-عدم توفر محارق فعالة لمعالجة تللك النفايات بالإضافة الى غياب الاسلوب الجيد للتشغيل

والصيانة المستمرة والمستدامة.

r-بعض المستشفيات في محافظات القاهرة الكبرى تفتقر إلى نظام الادارة الجيد لنفاياتها من

خلال الأسلوب المنبع في عمليات جمع ونقل وخزن النفايات.

r-إن مجموع ما تتنجه المستشفيات من نفايات بنوعيها الخطرة وغير الخطرة يساهم في وني

الإضرار بالبيئة، غير أن النفايات الطبية في حال عدم معالجنها تساهم بدرجة عالية في

تدمير النظم الطبيعية البيئية؛

ع-إن التخلص من النفايات الكيمبائية ذات المركبات عالية السمية دون معالجة له تأثنيرات

وخيمة على الصحة العامة والبيئة. 


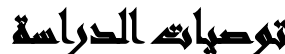

\begin{tabular}{|c|c|c|c|}
\hline عن تطبية التسئولة التوصية & كيفية وخطوات تنفيذ & التوصية & p \\
\hline 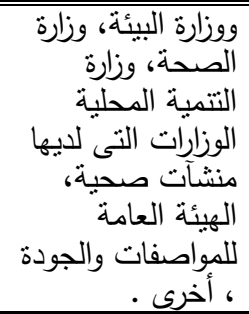 & 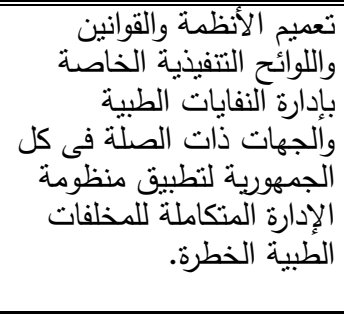 & 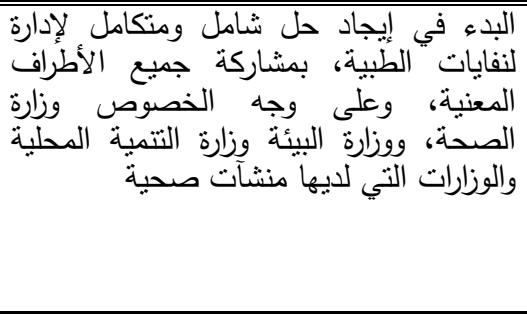 & $\overline{11}$ \\
\hline 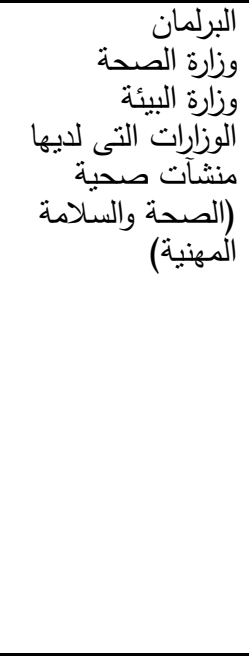 & 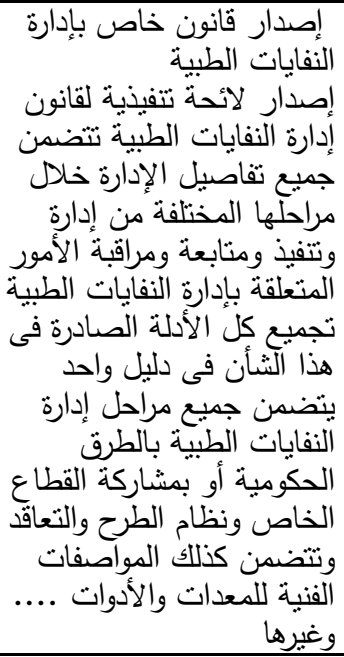 & 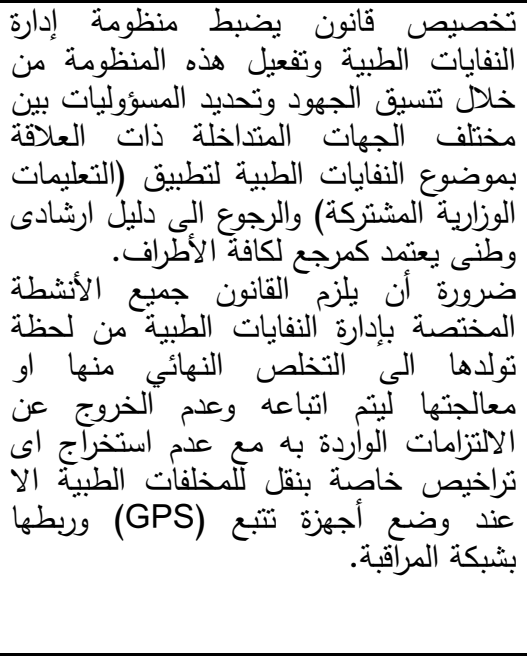 & $r$ \\
\hline وزارة وزارة البيئة والصحة & الجهات ذات الصنة مختصة من & 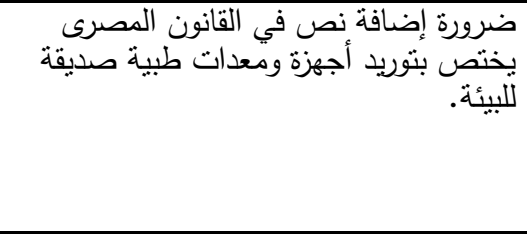 & $r$ \\
\hline لجنة مشكلة من الجهات & 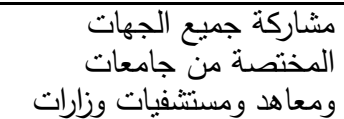 & لكافية الأطراف والإليل الإشادى وطني بعتمد كمرجع & $\varepsilon$ \\
\hline البيأة وزارة التمية، وزارة & عمل دورات تدريبية وورشة جميع الجهات & 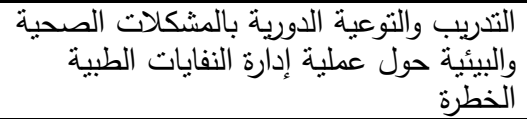 & 0 \\
\hline وزارة الصحة & 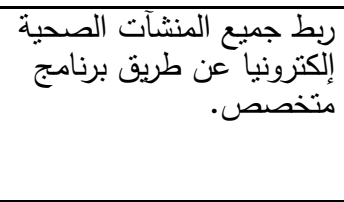 & 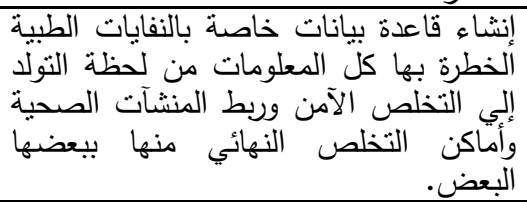 & 7 \\
\hline
\end{tabular}


مجلة العلوم البيئية

معهد الدراسات والبحوث البيئة - جامعة عين شمس لئس

\section{المرأing}

برنامج الأمم المتحدة للبيئة، مبادئ فنية بشأن الإدارة السليمة بيئيا للنفايات الطبية الإحيائية

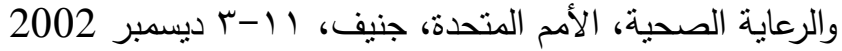

المعهد العربي الإنماء الددن، ندوة "الإدارة البيئية للنفايات في المدن العربية"، حلب، الجمهورية العربية السورية، المنية 2004

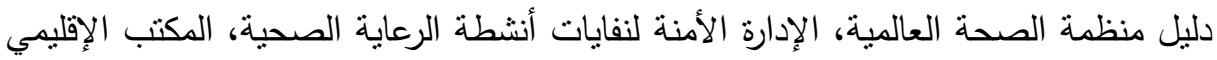

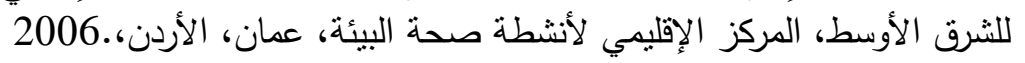

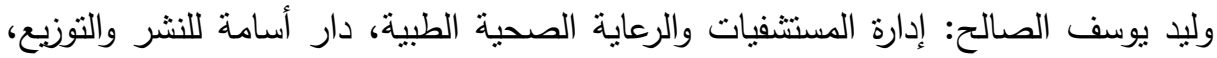
الطبعة الأولى، عمان، الأردن، الرعاية 2011

سعد علي العنزي: الإدارة الصحية، دار اليازوري العلمية للنشر والتوزيع، عمان، الأردن، 2012

سراي أم السعد: دور الإدارة الصحية في التسبير الفعال للنفايات الطبية في ظل ضوابط الإبة

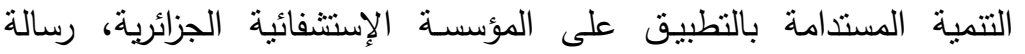

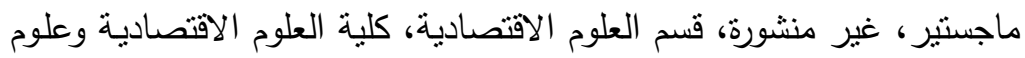
التسيير والعلوم التجارية، جامعة فرحات عباس سطيف، الجزائر، 2012

عبد السلام محمد داؤود: دراسة إدارة النفايات الطبية في مستشفيات مدينة شندي، مجلة جامعة شندي، 2013

رشا صلاح مهدى: دراسة كفاءة محارق النفايات الطبية فى مستشفيات الحلة فى محافظة بابل كلية الهندسة، جامعة بابل، 2014

دليل إرشادي لوزارة البيئة المصرية، إدارة نفايات الرعاية الصحية في مصر ، .2015 عصام الحناوي: قضايا البيئة في مئة سؤال وجواب، مجلة البيئة والتتمية، الطبعة الأولى لئي 2015

محمود محمد ضيفة: دراسة إدارة نفايات الرعاية الصحية بمستثفى السلاح الطبى أم درمان، رسالة ماجستير غير منشورة، جامعة الخرطوم، 2015

(Nightingale institute for health environment (HCWM. 2005.

hoope, Ravanello and mello . 2006.

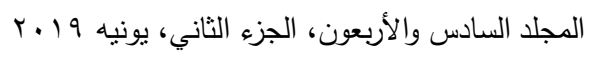


Reference of the International Committee of the Red Cross, Medical Waste Management, 2011.

United Nations, Department for Economic and Social Information and Policy Analysis, Statistics Division, Glossary of Environment Statistics, Series F, No 67, New York, 2014.

Reference of United states environmental protection agency, guide to pollution prevention for selected hospital waste stream, 2016

\title{
EVALUATION OF HAZARDOUS MEDICAL WASTES MANAGEMENT SYSTEM IN GREAT CAIRO GOVERNORATES
}

Fawkia E. A. El-Sayed ${ }^{(1)}$; Mahmoud M. A.Sobh ${ }^{(2)}$

Nehal M. F. El-Shahat ${ }^{(1)}$; Gehad A.Abou El-Ata ${ }^{(3)}$

1) Institute of Environmental Studies and Research, Ain Shams University 2) Facul ty of Commerce, Ain Shams University 3) Qasr ElEini Faculty of Medicine, Cairo University

\begin{abstract}
This study's purpose is to evaluate the system management of medical hazardous wastes in Great Cairo governorates (Cairo, Qalubia, Giza) across the last two decades since issue of the Environment Protection Law No. 4 of 1994 and its executive regulation. Since then Egypt has become concerned with setting a sustainable integrated system for hazardous wastes management that includes all economic institutions and activities in different areas of the state. In this system, all ministries and multiple institutions, national and international organizations in Egypt cooperate which on top are Ministry of Environment Affairs, Ministry of Health and Population in addition to several universities. The activities of Hazardous Wastes Management in
\end{abstract}

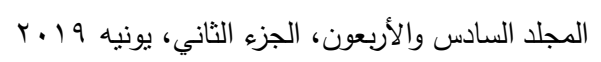


health care establishments have shown increasing commitment of health organizations towards principles, rules and procedures and the guidelines manual of secure for sound, secure and sustainable handling of hazardous wastes. However, there still several economic institutions and organizations don't apply safe integrated and sustainable handling system for hazardous wastes in the sound integrated environmental and health and economic management, which necessitates reviewing most of what related to this issue and to find out the alternative suitable solutions that achieve compromise with law and its conditions.

Despite the efforts made by all institutions in the management of medical waste, there are many procedures that must be considered to address several challenges and shortcomings in the management of hazardous waste in health care facilities and to minimize the negative effects of these challenges. These challenges are related to the behavior of employees, suppliers and suppliers who deal with thousands of health care facilities and activities in most parts of the country.

The researchers follow the descriptive approach in analysis of information and statistical data. The sample items (24) are distributed due to sex (male/female), education level (university and above certificate-medium- below medium), age stage, and the administrative level (higher management - medium - executive); including also three kinds of hospitals (governmental - private - and civil societies). The statistical method is used for testing measurement tools and checking validity of hypotheses statistical approaches and deducing results. The most important results are:

1. There is a remarkable shortness in efficient incinerators for handling wastes and absence of proper style of use, operation, and maintenance.

2. Hospitals in Great Cairo are missing the good management system of their wastes regarding collecting, transporting, and storing wastes.

Study Most important recommendations:

1. The necessity for finding out comprehensive integrated solutions for the problem of medical hazardous wastes in cooperation with all intended parties, particularly, Ministry of Health and competent authorities.

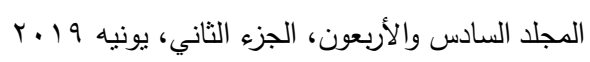




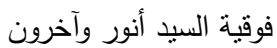

2. The necessity to find out alternative techniques that will be proper environmentally and economically such as closed sterilization to avoid pollution. 